\title{
Autoimmunity at the ocular surface: pathogenesis and regulation
}

\author{
ME Stern ${ }^{1}$, CS Schaumburg ${ }^{1}$, R Dana $^{2}$, M Calonge $^{3}$, JY Niederkorn $^{4}$ and SC Pflugfelder ${ }^{5}$
}

\begin{abstract}
A healthy ocular surface environment is essential to preserve visual function, and as such the eye has evolved a complex network of mechanisms to maintain homeostasis. Fundamental to the health of the ocular surface is the immune system, designed to respond rapidly to environmental and microbial insults, whereas maintaining tolerance to self-antigens and commensal microbes. To this end, activation of the innate and adaptive immune response is tightly regulated to limit bystander tissue damage. However, aberrant activation of the immune system can result in autoimmunity to self-antigens localized to the ocular surface and associated tissues. Environmental, microbial and endogenous stress, antigen localization, and genetic factors provide the triggers underlying the immunological events that shape the outcome of the diverse spectrum of autoimmune-based ocular surface disorders.
\end{abstract}

\section{INTRODUCTION}

The eye is arguably the most vital sensory organ for survival, and as such has evolved a diverse repertoire of mechanisms to preserve visual function. Communication between the ocular surface tissues and secretory glands through the central nervous system directs production of the tear film needed to preserve a smooth optical surface, ocular surface comfort, epithelial cell health, and provide protection from environmental insults and infection. Immunoregulatory mechanisms are also present within these tissues to prevent or resolve inflammation and maintain homeostasis. Indeed, the immune system is central to host protection, designed to respond efficiently to environmental and pathogenic insults, whereas maintaining tolerance to self-antigens and commensal microbial flora. Activation is tightly regulated and requires the coordinated effort of the innate and adaptive immune responses. The innate immune system is the first-line of defense and functions to control initial infection and coordinate the adaptive immune response, which culminates in activation of antigen-specific $\mathrm{T}$ and $\mathrm{B}$ cells, decreased microbial burden and generation of immunological memory to these foreign invaders. However, aberrant activation of the immune system may result in autoimmunity to self-antigens localized to the ocular surface and associated tissues.
Ocular surface autoimmune diseases encompass a diverse spectrum of pathologies and manifest as ocular specific (e.g., Dry Eye, Mooren's ulcerative keratitis), systemic (e.g., Sjögren's syndrome, ocular cicatricial pemphigoid (OCP)), or occur secondary to other common autoimmune diseases (e.g., rheumatoid arthritis, systemic lupus erythematosus (SLE)). Aberrant activation of the innate and adaptive immune responses underlies the immunopathogenesis of these disorders. The etiologies are unknown, but the general hypothesis predicts a combination of excessive or atypical stimuli and/or immunoregulatory dysfunction, combined with genetically predisposed factors and/or hormone imbalance provides an environment conducive to activation of autoreactive lymphocytes. These autoreactive $\mathrm{T}$ and $\mathrm{B}$ cells are the basis of autoimmune-mediated pathology. Recent insights have provided a more refined appreciation for when and how these cells are activated and to their various functions. The emerging view suggests that the autoimmune response is shaped early-on after provocation by foreign and/or endogenous stimuli, and can be perpetuated by both T-cell-dependent and -independent mechanisms. Indeed, differences in these immunological events underlie the diversity of ocular surface autoimmune syndromes, and may also explain why some patients within a particular disease population are refractory to an otherwise effective treatment paradigm.

\footnotetext{
${ }^{1}$ Biological Sciences, Inflammation Research Program, Allergan, Irvine, CA, USA. ${ }^{2}$ Department of Ophthalmology, Schepens Eye Research Institute and Massachusetts Eye and Ear Infirmary, Harvard Medical School, Boston, MA, USA. ${ }^{3}$ IOBA, University of Valladolid, Valladolid, Spain. ${ }^{4}$ Department of Ophthalmology, Southwestern

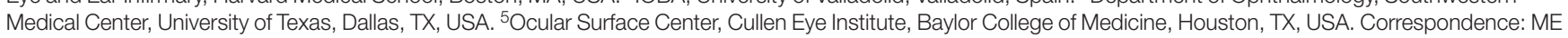
Stern (stern_michael@allergan.com)

Received 1 February 2010; accepted 14 April 2010; published online 19 May 2010. doi:10.1038/mi.2010.26
} 


\section{A HEALTHY OCULAR SURFACE ENVIRONMENT Lacrimal functional unit and the stable tear film}

The lacrimal functional unit unifies the complex reflex network connecting the sensory tissues and secretory glands that provide homeostasis on the ocular surface. The fundamental role of the lacrimal functional unit is to provide the stable tear film needed to preserve a smooth optical surface, comfort, epithelial cell health, and protection from environmental and microbial insults. It is composed of the ocular surface tissues (cornea, corneal limbus, conjunctiva, conjunctival blood vessels, eyelids), the tear-secreting machinery (main and accessory lacrimal glands, meibomian glands, conjunctival goblet, and epithelial cells), and their neural connections. ${ }^{1,2}$ The lacrimal functional unit is tightly controlled by neural input from the ocular surface tissues. In fact, the cornea is the most highly innervated surface tissue of the body and the main sensory epithelial surface of the lacrimal functional unit. ${ }^{3}$ Subconscious stimulation of the corneal nerve endings triggers afferent impulses through the ophthalmic branch of the trigeminal nerve $(V)$, which integrate in the central nervous system and the paraspinal sympathetic tract, in turn generating efferent secretomotor impulses that stimulate secretion of the healthy tear film. Any one of several sensory stimuli, for example, pain, microbial-environmental insult, and emotion can stimulate the tear-secreting reflex. By contrast, inhibition of afferent sensory input with general anesthesia disrupts the lacrimal functional unit and blocks normal tear production. ${ }^{4}$ An unstable tear film contributes directly to inflammation, underscoring the importance of the lacrimal functional unit in maintaining a healthy ocular surface environment. ${ }^{1,2}$

\section{Immunoregulation}

Immunoregulation refers to the tolerance and modulatory mechanisms responsible for tightly controlling the innate and adaptive immune response to limit bystander tissue damage after stress and/or microbial assaults. Central tolerance occurs in the primary lymphoid organs to reduce the number of mature autoreactive T cells (thymus) and B cells (bone marrow); however, it is overwhelmingly clear that self-reactive cells exist in healthy individuals. ${ }^{5}$ Accordingly, peripheral tolerance mechanisms function to suppress these cell types and to provide an additional layer of control for regulating both induction and expression of immunity. Like other mucosal sites the ocular surface also contains its own local lymphoid tissues, that is, conjunctiva-associated lymphoid tissue situated to sample antigens and maintain tolerance to commensal flora. ${ }^{6,7}$ The eye has evolved to include a number of mechanisms to modulate inflammation after environmental or microbial stress on the ocular surface (Figure 1).

Anti-inflammatory factors limit acute inflammation on the ocular surface. The ocular surface tissues contain a variety of factors to reduce inflammation-induced pathology in the lacrimal functional unit (Figure 1a). The anti-inflammatory cytokine transforming growth factor (TGF)- $\beta$ is present on the ocular surface, ${ }^{8}$ and has profound suppressive affects on resident dendritic cell (DC) maturation in the cornea, ${ }^{9}$ autoreactive T-cell proliferation, differentiation, and survival, ${ }^{10}$ and Treg differentiation and maintenance. ${ }^{11,12}$ In addition, the activity of the proinflammatory cytokine interleukin (IL)-1 is modulated by the IL-1 receptor antagonist, ${ }^{13}$ expressed and secreted by corneal epithelial cells. ${ }^{14}$ Vasoactive intestinal peptide also seems to be protective by modulating pro- and anti-inflammatory cytokine expression to favor suppression ${ }^{15}$ (Figure 1a). Hormones have also been implicated in curbing inflammation and maintaining homeostasis. ${ }^{16}$ In addition, the corneal epithelium expresses soluble vascular endothelium growth factor receptor-1 and membrane-expressed vascular endothelium growth factor $\mathrm{R}-3,{ }^{17}$ which sequester the angiogenic factors vascular endothelium growth factor-A and vascular endothelium growth factor-C, respectively, to reduce angiogenesis that may limit inflammatory cell infiltration after ocular stress. ${ }^{18}$ Additional peripheral immunoregulatory mechanisms also limit access and effector function of autoreactive $T$ cells within the ocular surface tissues (Figure 1c). For example, the programmed death ligand-1 is a key regulatory molecule, which helps to protect the ocular tissues from T-cell-mediated damage, for example, during corneal transplant and Dry Eye disease. ${ }^{19-22}$

Regulatory T cells. Different subsets of regulatory T cells have been suggested to modulate the immune response within the ocular surface tissues and regional lymphoid organs. Distinct cell subsets include unconventional (e.g., CD $8+, \gamma \delta$ and NKT cells) and conventional Tregs (CD4+). Conventional Tregs are thymus-derived, naturally occurring Tregs (nTreg), or can be induced in response to specific antigens (iTreg). Immunosurveillance by CD $8+\mathrm{T}$ cells, $\gamma \delta \mathrm{T}$ cells, and NKT cells present within the conjunctiva-associated lymphoid tissue of healthy subjects ${ }^{23,24}$ may provide protection against autoimmunity, as shown at other mucosal sites. ${ }^{25}$ These cell types likely contribute to both anti-microbial defense and suppression of autoreactive lymphocyte differentiation and/or function, the latter, by secreting TGF- $\beta$ and/or IL-10 (Figure 1a). CD $8+$ T cells predominant the ocular surface epithelium, ${ }^{24}$ and a subset exert regulatory function during anterior chamber-associated immune deviation. ${ }^{26,27}$ The functional role of unconventional regulatory cell subsets on the ocular surface is widely unknown.

In the context of ocular surface autoimmunity, conventional $\mathrm{CD} 4{ }^{+} \mathrm{CD} 25^{\mathrm{hi}} \mathrm{Foxp}{ }^{+}$nTregs confer protection from full-blown T-cell-mediated experimental autoimmune lacrimal keratoconjunctivitis (ALKC). However, when nTregs are depleted, mice develop extensive disease. ${ }^{28} \mathrm{CD} 4{ }^{+} \mathrm{CD} 25^{\text {hi }}$ Foxp $3^{+}$cells also mute inflammation when co-transferred with ALKC-specific pathogenic CD4 + T cells into T-cell-deficient nude mice, ${ }^{29}$ further highlighting the suppressive role of nTregs in ocular surface autoimmunity. To date, the specific mechanisms used by nTregs to inhibit T-cell activation, differentiation, proliferation, and effector function have not been extensively elucidated. Tregs have been suggested to mediate suppression by: (i) releasing soluble factors (e.g., TGF- $\beta$, IL-10) (ii) cell-cell contact that disables effector $\mathrm{T}$ cells and/or antigen presenting cells (APCs), and/or (iii) competing for soluble factors (e.g., IL-2 sequestration 


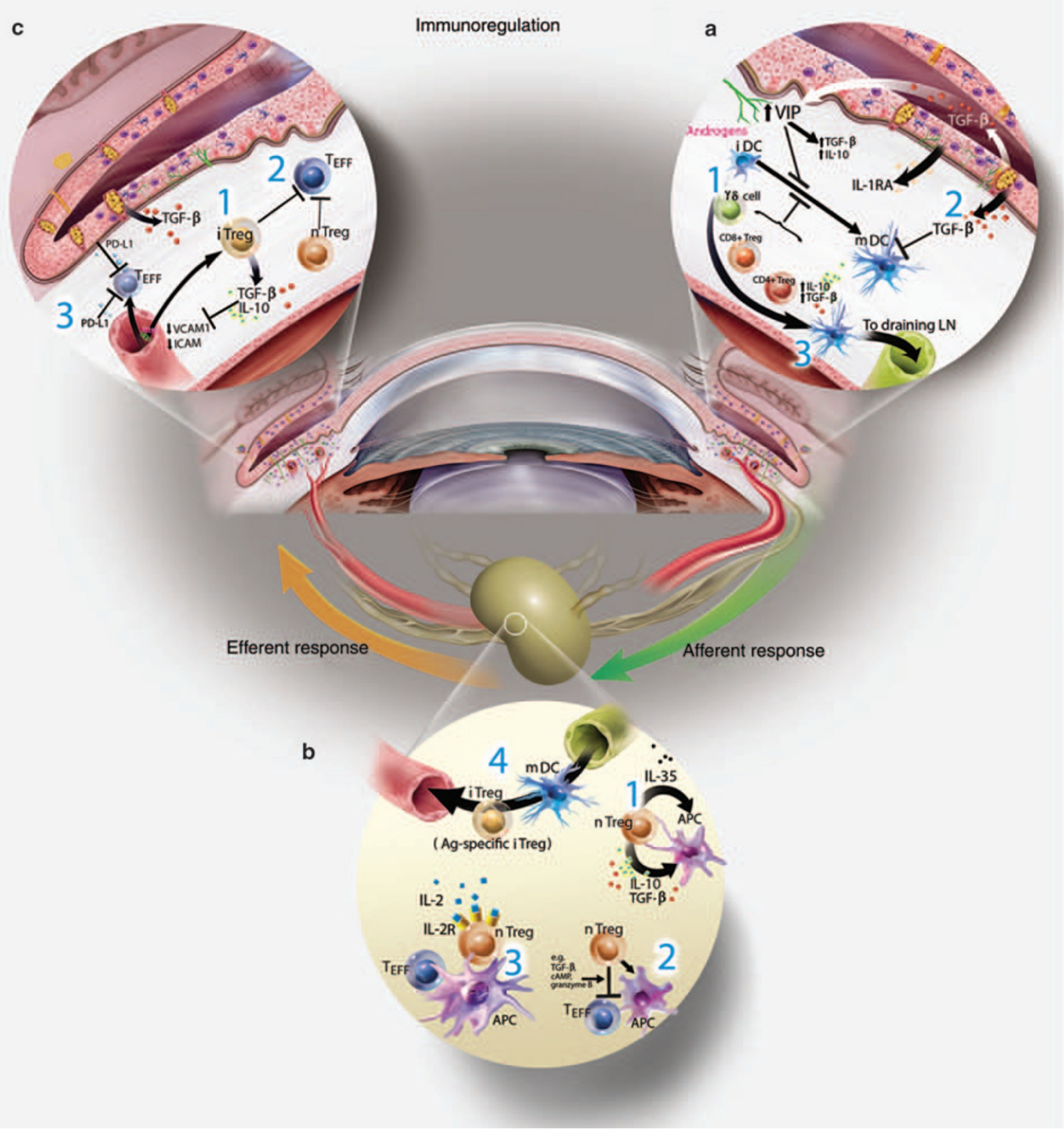

Figure 1 Immunoregulation on the ocular surface: (a) the ocular surface tissues contain a variety of soluble and cellular factors to reduce inflammation-induced pathology in the lacrimal functional unit. Those implicated in immunoregulation within the ocular surface tissues include: (1) nTregs (e.g., CD4+, CD8+, $\gamma \delta$, and NKT cells), which include many of the conjunctival intraepithelial lymphocytes, are thought to dampen or inhibit the inflammatory/autoimmune response on the ocular surface. (2) The anti-inflammatory cytokine transforming growth factor (TGF)- $\beta$ is present on the ocular surface, and has profound suppressive affects on resident dendritic cell (DC) maturation in the cornea, autoreactive T-cell proliferation, differentiation, and survival, and Treg differentiation and maintenance. The activity of the potent acute response proinflammatory cytokine interleukin (IL)-1 is modulated by the IL-1 receptor antagonist (IL-1RA), expressed and secreted by corneal and conjunctival epithelial cells. Vasoactive intestinal peptide (VIP) also seems to be protective; VIP secreted by sensory nerve endings in the cornea increases production of TGF- $\beta$ and IL-10 and inhibits expression of the proinflammatory cytokines/chemokines, IL-1 $\beta$, tumor necrosis factor (TNF)- $\alpha$, interferon (IFN)- $\gamma$, and CXCL2. Hormones are also implicated in curbing inflammation and maintaining homeostasis. In addition, the corneal epithelium also expresses vascular endothelium growth factor (VEGF) receptor-1 to sequester VEGF and reduce neovascularization. (3) APCs bearing self-antigen derived at the ocular surface may migrate to the regional lymph nodes to induce antigen-specific Tregs (iTregs). (b) Immunoregulation in the lymphoid organs: $n$ Tregs may exert their immunosuppressive function by (1) releasing soluble factors (e.g., TGF- $\beta$, IL-10), (2) cell-cell contact, which disables pathogenic effector T cells (Teff) and/or APCs, and/or (3) competing for soluble factors (e.g., IL-2). (4) Inducible Tregs (iTregs) may use similar mechanisms to inhibit cells bearing or responding to autoantigens. It is possible that these Treg-dependent mechanisms may also function within the ocular surface tissues. (c) Other peripheral immunoregulatory mechanisms: additional mechanisms also limit access and effector function of autoreactive T cells within the ocular surface tissues: (1) TGF- $\beta$ and (2) nTregs and iTregs are suggested to suppress infiltrating autoreactive lymphocytes and (3) low-level expression of integrins in the healthy ocular surface endothelial cells, coupled with expression of the programmed death ligand-1 (PD-L1), negatively regulates activated T cells within the ocular surface tissues. 
Table 1 Ocular surface autoimmune diseases

\begin{tabular}{|c|c|c|}
\hline Dry Eye & Ocular surface epithelium & $\begin{array}{l}\text { Increased proinflammatory cytokines (e.g., IL- } \\
1 \beta \text {, TNF- } \alpha \text {, IL-17, IFN- } \gamma \text { ); CD4 + T-cell infiltration } \\
\text { within the conjunctiva; goblet cell loss; squa- } \\
\text { mous metaplasia }\end{array}$ \\
\hline Mooren's ulcerative keratitis & $\begin{array}{l}\text { Corneal and conjunctival epithelium, } \\
\text { Sclera }\end{array}$ & $\begin{array}{l}\text { Infiltration of neutrophils, plasma cells, lym- } \\
\text { phocytes, and eosinophils }\end{array}$ \\
\hline \multirow[t]{2}{*}{ Sjogren's syndrome } & $\begin{array}{l}\text { Primary: lacrimal gland, ocular surface } \\
\text { goblet cells }\end{array}$ & $\begin{array}{l}\text { CD4 + T-cell and B-cell infiltration, autoantibod- } \\
\text { ies; goblet cell loss; squamous metaplasia }\end{array}$ \\
\hline & $\begin{array}{l}\text { Secondary: similar features associated } \\
\text { with example rheumatoid arthritis }\end{array}$ & \\
\hline Ocular cicatricial pemphigoid & Basement membrane of epithelium & $\begin{array}{l}\text { Autoantibody and complement deposition in } \\
\text { basement membrane of the conjunctiva; mac- } \\
\text { rophages and B cells in the stroma; fibrosis and } \\
\text { scarring }\end{array}$ \\
\hline Stevens-Johnson syndrome & Epithelium: mucosa and skin & $\begin{array}{l}\text { T-cell infiltration (CD4 +, CD8 + ), NK cells; epi- } \\
\text { thelial cell apoptosis; fibrosis; scarring; opacifi- } \\
\text { cation of the cornea }\end{array}$ \\
\hline \multicolumn{3}{|l|}{ Systemic autoimmunity following allograft } \\
\hline Graft vs. host disease & $\begin{array}{l}\text { Skin, mucous membranes, eye (e.g., } \\
\text { conjunctiva, lacrimal gland) }\end{array}$ & $\begin{array}{l}\text { T-cell infiltration; ocular surface manifestations } \\
\text { include Dry Eye, KCS, pseudomembranous } \\
\text { conjunctivitis, conjunctival fibrosis, lacrimal, } \\
\text { and meibomian gland disease, corneal epithe- } \\
\text { lial sloughing }\end{array}$ \\
\hline
\end{tabular}

Abbreviations: IFN, interferon; IL, interleukin; KCS, keratoconjunctivitis sicca; TNF, tumor necrosis factor.

through high-level expression of the IL-2 receptor, CD25). The crux of these suppressive roles are thought to occur predominantly in the regional lymphoid organs (Figure 1b), or possibly within the ocular surface tissues (Figure 1c). The suppressive function of antigen-specific iTregs in the context of the eye is also an area of intense investigation.

\section{CLINICAL SPECTRUM OF OCULAR SURFACE DISEASE AND ANIMAL MODELS}

The ocular surface and its supporting tissues in the lacrimal functional unit are targets of a variety of autoimmune reactions, which can severely affect quality of life and threaten vision (Table 1). The susceptibility of the lacrimal functional unit to autoimmune inflammation may be related to its exposure to desiccating stress, leakage of autoantigens from secretory cells, and perpetual challenges by microbial and environmental antigens, all of which can disrupt the delicate balance between the resident immunoregulatory mechanisms and proinflammatory protective factors. As a component of the mucosal immune system, the lacrimal functional unit may also be targeted in systemic autoimmune conditions. In the following section, we highlight (i) some of the features of autoimmune-based inflammatory diseases initiated in either the lacrimal functional unit or systemically and (ii) some of the most popular animal models used to gain insights into the immunopathogenesis of two common autoimmune diseases, Dry Eye and Sjögren's syndrome.

\section{Localized disease}

Dry Eye is by far the most common autoimmune condition affecting the ocular surface. The estimated prevalence of Dry Eye ranges from 0.3 to $33 \%$ of the population depending on the definition and the population studied. ${ }^{30}$ Dry Eye can have a considerable effect on visual function, daily activities, social and physical functioning, workplace productivity, and quality of life. ${ }^{31,32}$ Studies investigating Dry Eye patients and mouse models have found evidence of immune-based inflammation in the tears and ocular surface tissues. Evidence suggests that inflammation and dysfunction of the lacrimal functional unit fuels the autoimmune reaction (Figure 2). Autoreactive CD4+ $\mathrm{T}$ cells are targeted to the ocular surface in which they release cytokines that further impair secretory function and homeostasis. Chronic inflammation of the lacrimal functional unit leads to increased corneal permeability, apoptosis of surface epithelial cells, and in more severe cases, loss of goblet cells and increased production of cornified envelope precursors, culminating in a non-wettable irregular surface associated with reduced corneal optical clarity.

A major advance in Dry Eye therapy has been incorporation of anti-inflammatory/immunomodulatory therapy. These therapies are recommended when ocular surface epithelial disease is noted clinically and include topical cyclosporine A, topical corticosteroid, oral omega-3 essential fatty acid supplements, and oral tetracyclines. ${ }^{33}$ These current therapies have broad anti-inflammatory activities. Therapies targeting 


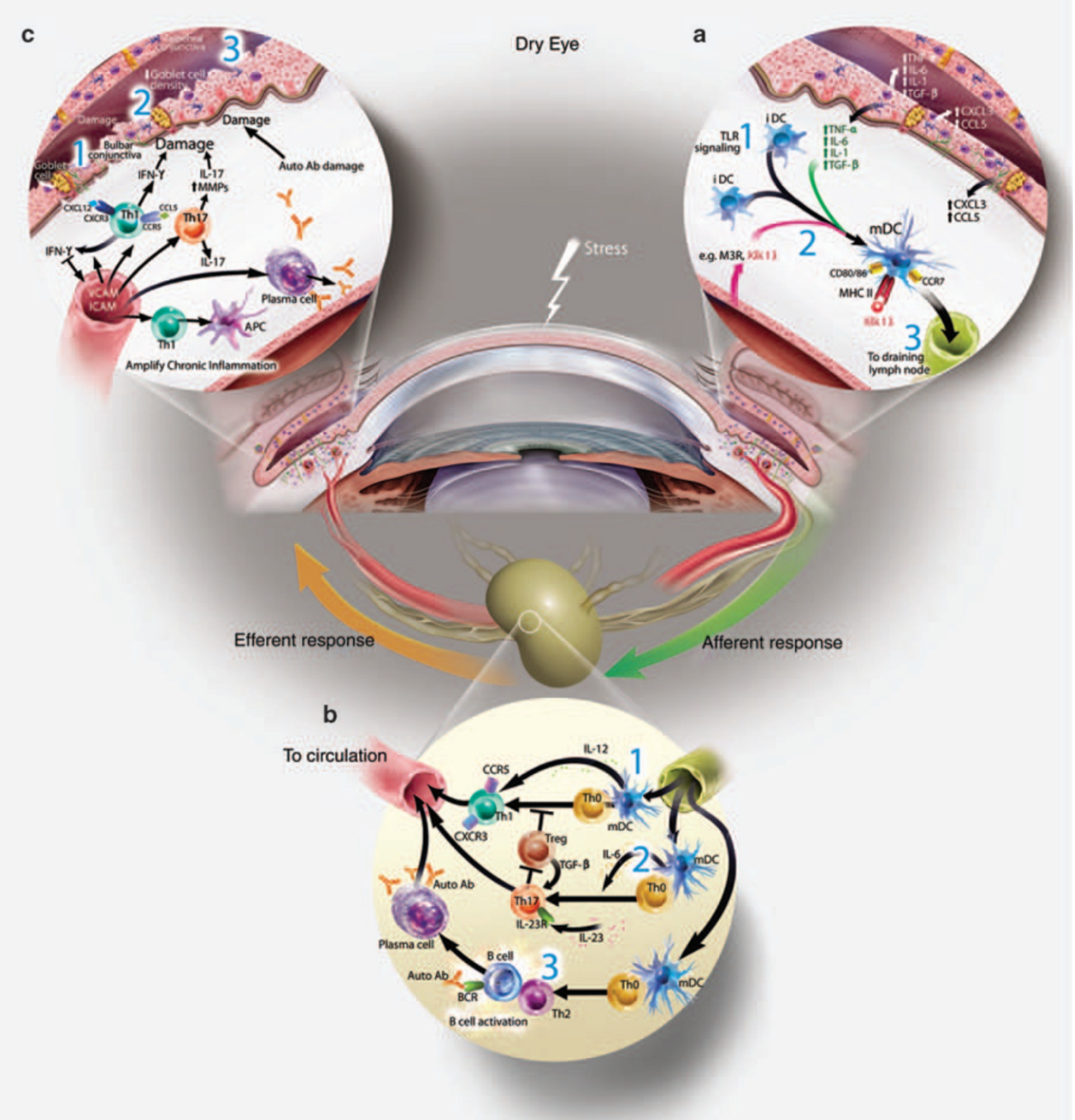

Figure 2 The immunopathogenesis of Dry Eye disease. (a) Afferent autoimmune response: stress to the ocular surface triggers the initial events suggested to initiate autoimmunity. (1) Induction of proinflammatory factors (cytokines, chemokines, and matrix metalloproteinases (MMPs)) is a hallmark of ocular surface autoimmunity and may be initiated by stress signal transduction pathways or possibly by Toll-like receptor (TLR) signaling (after microbial infection or aberrant endogenous activation). Acute response cytokines, such as interleukin (IL)-1 $\alpha$, IL-1 $\beta$, tumor necrosis factor (TNF)- $\alpha$, and IL- 6 are elevated in patients with Dry Eye. IL-1 and TNF- $\alpha$ amplify inflammation on the ocular surface through processes, such as activation of APCs. (2) Evidence suggests that APCs internalize autoantigen, for example, type III muscarinic receptor $\left(\mathrm{M}_{3} R\right)$, Kallikrein $(\mathrm{KIK}) 13$, process and present immunogenic epitopes on MHCIl, upregulate expression of costimulatory molecules, for example, CD80, and CD86 and (3) the chemokine receptor, CCR7, which directs the activated APCs to the draining cervical lymph node. (b) Efferent activation of autoreactive lymphocytes: the local cytokine milieu influences T-cell differentiation. (1) IL-12 present within the ocular surface tissues and produced by mature APCs, combined with interferon (IFN)- $\gamma$ likely influences the activation and differentiation of autoreactive Th1 cells. (2) By contrast, elevated IL- 6 in the presence of transforming growth factor (TGF)- $\beta$ and IL-23 may skew differentiation toward Th17 cells. (3) B cells are also predicted to have a role in Dry Eye as shown in Sjögren's syndrome. In this scenario, Th2 cells provide help to autoreactive B cells and promote clonal expansion, somatic hypermutation, isotype switching, affinity maturation and plasma cell differentiation into autoantibody-secreting cells. Alternatively, B cells may be activated independently of T cells, for example, TLR and BAFF signaling. Efferent trafficking of autoreactive T cells to the ocular surface tissues is widely thought to be directed by adhesion molecules (e.g., LFA-1, VLA-4) and chemokine receptors (e.g., CCR5 and CXCR3) that respond to cognate ligands expressed on the ocular surface (e.g., ICAM-1, CCL5, and CXCL10). (c) Efferent effector function of autoreactive lymphocytes: Autoreactive Th1 and Th17 cells present during the immunopathogenesis of Dry Eye potentiate the chronic autoimmune response and have pathological consequences. For example, Th1 cells stimulate APCs to secrete proinflammatory cytokines and are a prominent source of interferon (IFN)- $\gamma$, which induces expression of a multitude of proinflammatory factors, pro-apoptotic proteins and causes direct tissue destruction. IFN- $\gamma$ alters mucins on corneal epithelial cells that have devastating effects on ocular surface integrity. IFN- $\gamma$ is linked to (1) epithelial cell apoptosis, (2) reduced goblet cell density, and (3) squamous metaplasia. IL-17 produced by infiltrating Th17 cells increases MMP3/9 expression and induces corneal epithelial barrier dysfunction. Furthermore, autoantibodies may bind to target antigens causing direct tissue destruction. 
key inflammatory mediators may prove more effective in the future.

Animal models of Dry Eye. Canine model: Dry Eye common in some canine breeds, for example, Alapaha Blue Blood Bulldog, West Highland White Terrier, has been useful in uncovering immunopathological mechanisms. Clinical and histopathological disease in Dry Eye dogs is similar to humans with reduced tear production, marked inflammatory cell infiltration into the cornea, conjunctiva, lacrimal glands, coupled with epithelial cell apoptosis within the lacrimal functional unit and widespread mucin abnormalities in the tear film. ${ }^{34-36}$ Successful intervention with T-cell inhibitors in the canine model shows utility for use in preclinical development, ${ }^{37,38}$ however, advent of small animal models has greatly accelerated discovery.

Experimental Dry Eye: ALKC Various models of experimental Dry Eye have been suggested in mice and rabbits including induction with (i) concanavalin A, (ii) by immunization with lacrimal autoantigens, (iii) adoptive transfer autologously activated lymphocytes, or (iv) exposure to desiccating stress (ALKC). ${ }^{39}$ The mouse model of ALKC is based on the concept that environmental stress coupled with altered tear film disrupts ocular surface homeostasis and incites a localized autoimmune response that is chronic Dry Eye disease. ALKC is induced by exposing mice to constant airflow in low humidity, that is, desiccating environmental stress (DS) combined with administration of an anticholinergic, with the primary function of lowering aqueous tear production, that is, contributing to altered tear film. ${ }^{28}$ Under these conditions mice show rapid and coordinated upregulation of proinflammatory cytokines that precedes CD $4+\mathrm{T}$-cell activation in the secondary lymphoid organs. By 5 days post-DS, a mixed population of infiltrating inflammatory cells including CD4 + $\mathrm{T}$ cells (Th1 and Th17) are detected within the ocular surface tissues, along with elevated levels of Th1- and Th17derived cytokines, interferon (IFN) $-\gamma$ and IL-17. The rapid $\mathrm{T}$-cell response argues that these autoreactive cells are poised for activation in the periphery. Accumulation of T cells and their derivatives correlates with decreased goblet cell density in the conjunctiva, epithelial cell apoptosis, increased corneal permeability, and squamous metaplasia of the corneal surface. ${ }^{28,40-42}$

The importance of CD4 + T cells in Dry Eye is supported with adoptive transfer into T-cell-deficient recipient mice, which also serves as a robust model of T-cell-mediated ALKC. ${ }^{28}$ In fact, DS-primed CD4 + T cells isolated from mice exposed to DS for 5-10 days cause ALKC in nude recipient mice, although the nude mice are never exposed to DS. By 3 days post-transfer, the recipient mice show increased proinflammatory cytokine levels in the tears, extensive cellular infiltration into the conjunctiva, cornea and lacrimal gland, decreased tear production, and loss of goblet cells. CD4 $+\mathrm{T}$ cells are not detected within other organs of nude recipient mice confirming that DS-specific CD4 + T-cell homing and pathogenesis is restricted to lacrimal functional unit. This model offers the advantage of more precisely dissecting T-cell-specific aspects (effector and regulatory) that contribute to the development of, and protection from, ocular surface autoimmunity.

\section{Systemic autoimmunity}

Sjögren's syndrome. Sjögren's syndrome is one of the most common systemic autoimmune conditions occurring predominantly in women and affecting the salivary and lacrimal glands and mucosal tissues throughout the body. Severe sight-threatening Dry Eye may develop. The autoimmune reaction may initiate in the lacrimal or salivary glands, perhaps targeting acinar cell antigens that are exposed to the immune system by increased membrane trafficking as a result of viral infection or reflex overstimulation..$^{43}$ Viruses, including retroviruses, hepatitis $C$ virus, cytomegalovirus, and Epstein-Barr virus are implicated as initiating agents. ${ }^{44,45}$ The putative autoantigen seems to be shared by other involved tissues. Increased production of inflammatory cytokines and matrix metalloproteinases (MMPs) are detected in the involved secretory glands and tissues. ${ }^{46-48}$ Furthermore, the lacrimal and salivary glands become infiltrated with CD4+ T cells and autoantibody producing B cells. ${ }^{49-51}$ The Th1- and Th17-associated cytokines, IFN- $\gamma$, and IL-17, are associated with increased inflammation and glandular dysfunction in Sjögren's syndrome. ${ }^{52}$ Certain cytokines, such as IL- 1 have been noted to suppress lacrimal acinar secretion. ${ }^{53}$ To this point, a key feature of Sjögren's syndrome is early loss of reflex tearing that occurs before extensive lymphocytic infiltration of the glandular tissue. A number of circulating IgG autoantibodies have been detected in patients with Sjögren's syndrome. These include SS-A (antiRo) and anti-La. Anti-Ro reacts with two different polypeptides, Ro52 and Ro60. Ro52 is a type I IFN inducible protein that translocates to the nucleus in response to IFN- $\alpha$ stimulation. It has been found to either promote or abrogate inflammation. ${ }^{54}$ Glandular secretory dysfunction causes a profound decrease in tear volume, decreased concentration of lacrimal secretory proteins, and increased concentration of inflammatory cytokines in tears. ${ }^{48,55}$ Hence, alterations in tear volume and composition may initiate the events leading to lymphocyte infiltration. The ocular surface inflammation that develops in Sjögren's syndrome seems to be similar, albeit more severe than the inflammation in non-Sjögren's syndrome Dry Eye conditions. Increased production of IFN- $\gamma$ promotes development of conjunctival squamous metaplasia and loss of goblet cells. Greater MMP activity on the ocular surface increases the risk of developing keratolysis and sight-threatening corneal ulceration. ${ }^{46,56}$

Ocular therapy of Sjögren's syndrome is similar to nonSjögren's syndrome-associated Dry Eye, but because the ocular surface disease is more severe, anti-inflammatory therapy is indicated in all patients. To date, systemic immunomodulatory therapy has not been used in Sjögren's syndrome unless the condition is associated with rheumatoid arthritis; nonetheless, systemic treatment with immunomodulators, such as the B-cell inhibitor, rituximab (murine/human chimeric antiCD20 antibody), has shown promise in patients with primary Sjögren's syndrome based on recent retrospective studies and in early clinical trials. ${ }^{57,58}$ For example, rituximab decreased 
inflammatory markers in some patients, which was associated with increased salivary flow ${ }^{57}$ and reduced the need for high-dose corticosteroid treatment in a subset of patients. ${ }^{58}$ These studies highlight the potential for use of targeted immunomodulatory therapy in patients with Sjögren's syndrome and similar ocular surface syndromes.

Ocular cicatricial pemphigoid. OCP, also known as mucus membrane pemphigoid is a severe and potentially blinding disease. Patients show circulating autoantibodies to epithelial basement membrane constituents, including bullous pemphigoid antigens 1 and 2, laminin 5 (epiligrin), laminin 6 , collagen 7 , and $\beta 4$ integrin subunit. ${ }^{59}$ Diagnosis of OCP is based on detection of immunoglobulin or complement component 3 depositions in the basement membrane zone of the conjunctiva. The reported therapeutic response of this condition to B-cell neutralization with rituximab suggests circulating basement membrane zone autoantibodies have a key role in pathogenesis. ${ }^{60}$ The predominant clinical manifestation of $\mathrm{OCP}$ is progressive fibrosis and contracture of the conjunctiva that results from activation, hyperproliferation, and increased extracellular matrix production by conjunctival fibroblasts ${ }^{61}$ (Figure 3 ). This fibrotic process may obliterate the conjunctival fornices and lacrimal ducts resulting in severe Dry Eye. Progressive vascularization and fibroproliferation may involve the cornea and progress to blindness. Studies performed on conjunctival biopsies have reported an increase in CD4 $+\mathrm{T}$ cells and DCs in the epithelium and IL-2R-bearing T cells (CD4 + and CD8 +), macrophages and $B$ cells in the stroma ${ }^{62-64} \mathrm{Th} 2$ cells seem to amplify the fibrotic process through production of cytokines, such as IL-13 that stimulate resident fibroblasts to produce profibrotic cytokines, such as TGF- $\beta$, platelet-derived growth factor, basic fibroblast growth factor, and connective tissue growth factor, all of which are increased in the conjunctiva. ${ }^{65-67}$

Systemic immunosuppressive therapy is indicated for OCP. Therapies are typically administered in a stepwise manner based on disease severity and clinical response. First-line therapies include Dapsone, mycophenylate mofetil, and methotrexate. If these are not effective, cyclophosphamide, intravenous immunoglobulins or rituximab is considered. ${ }^{60,61}$ No single therapy has proven to be effective in all cases. Therefore, there is a definite clinical need for additional therapies that inhibit conjunctival fibrosis.

Stevens-Johnson syndrome. Stevens-Johnson syndrome is another severe cicatricial autoimmune disease affecting the ocular surface, initiated by drugs and microbial infections (herpes simplex virus, Epstein-Barr virus, mycoplasma, and coccidiomycosis) ${ }^{68}$ The risk of developing Stevens-Johnson syndrome is increased in individuals immunocompromized because of human immunodeficiency virus infection or SLE. ${ }^{68}$ The immunopathogenesis of Stevens-Johnson syndrome has not been fully elucidated; however, an initial manifestation of the disease is massive apoptosis of the epidermis and mucosal epithelium. This blast of apoptosis may occur through two mechanisms, activation of epithelial Fas ligand or by perforin released from cytotoxic T lymphocytes or NK cells. Fas ligand is expressed by keratinocytes and ocular surface epithelial cells and infiltrating $\mathrm{T}$ cells, Fas expression has also been reported to increase in keratinocytes from biopsies. ${ }^{69,70}$ Activation of the Fas signaling cascade may lead to widespread apoptosis in the ocular surface epithelia and skin. Early treatment with intravenous immunoglobulin has been reported to block activation of the Fas pathway. ${ }^{71}$ Release of perforin, a cytolytic protein found in the granules of drug-specific cytotoxic CD8 + $\mathrm{T}$ cells and NK cells can also initiate keratinolysis observed early during disease development. ${ }^{72}$ After the initial inflammation and epithelial apoptosis, the conjunctiva rapidly enters a fibrotic phase resulting in loss of the conjunctival fornices, inward contracture of the lid margins and neovascularization, and opacification of the cornea. Inflammatory destruction of the tear-secreting cells and obliteration of secretory ducts in the lacrimal and meibomian glands leads to severe chronic Dry Eye and ocular surface disease.

There is no consensus regarding the use of systemic antiinflammatory therapy for treatment of acute Stevens-Johnson syndrome. Systemic corticosteroid therapy has been reported to reduce epidermal loss, but use remains controversial. ${ }^{73}$ Intravenous immunoglobulin may inhibit the massive epithelial apoptosis in the skin and mucosal tissues. Amniotic membrane transplantation has been reported to reduce ocular surface inflammation and fibrosis. ${ }^{74}$ Therapy of chronic disease is aimed at suppressing inflammation that results from severe dryness and constant trauma from the scarred eyelids and in turning eye lashes. ${ }^{75}$

Animal models of Sjögren's syndrome. NOD mouse: The nonobese diabetic (NOD) mouse inherently lacks the full repertoire of tolerance mechanisms and is therefore genetically predisposed to spontaneous autoimmunity, which depending on the subline, may represent a variety of diseases including insulin-dependent diabetes mellitus, ${ }^{76} \mathrm{SLE},{ }^{77}$ thyroiditis ${ }^{78}$ and primary or secondary Sjögren's syndrome..$^{79-83}$ In the original NOD strain, $~ 60-80 \%$ of female mice develop type 1 diabetes, ${ }^{84}$ with a subset showing xerostomia and xerophthalmia reminiscent of secondary Sjögren's syndrome. ${ }^{79}$ Exocrine gland dysfunction is preceded by a variety of immunological changes including increased MMP activity, upregulation of proinflammatory cytokines, focal inflammatory cell infiltration $(\mathrm{CD} 4+\mathrm{T}$ cells $>>>\mathrm{CD} 8+\mathrm{T}$ cells and $\mathrm{B}$ cells) into the submandibular salivary and lacrimal glands, and elevated serum autoantibody levels, for example, anti-nuclear antibodies and anti-type III muscarinic receptor antibodies. ${ }^{79,81,85-89}$ The original NOD mouse has also been adapted to more specific disease phenotypes by constructing congenic major histocompatibility complex (MHC) strains, that is, the susceptibility chromosome region in the NOD mouse is replaced by a region from a resistant mouse or vice versa. Descendents of the original NOD mouse (MHC I- $\mathrm{A}^{\mathrm{g} 7}$ ) harboring congenic $\mathrm{H} 2 \mathrm{MHC}$ haplotypes, for example, NOD.B10-H2 $2^{b}$ developed a Sjögren's syndrome-like phenotype independently of insulitis and diabetes, ${ }^{82}$ therefore serving as a reliable model to study different aspects of clinical and histopathological disease with similarity to primary Sjögren's 


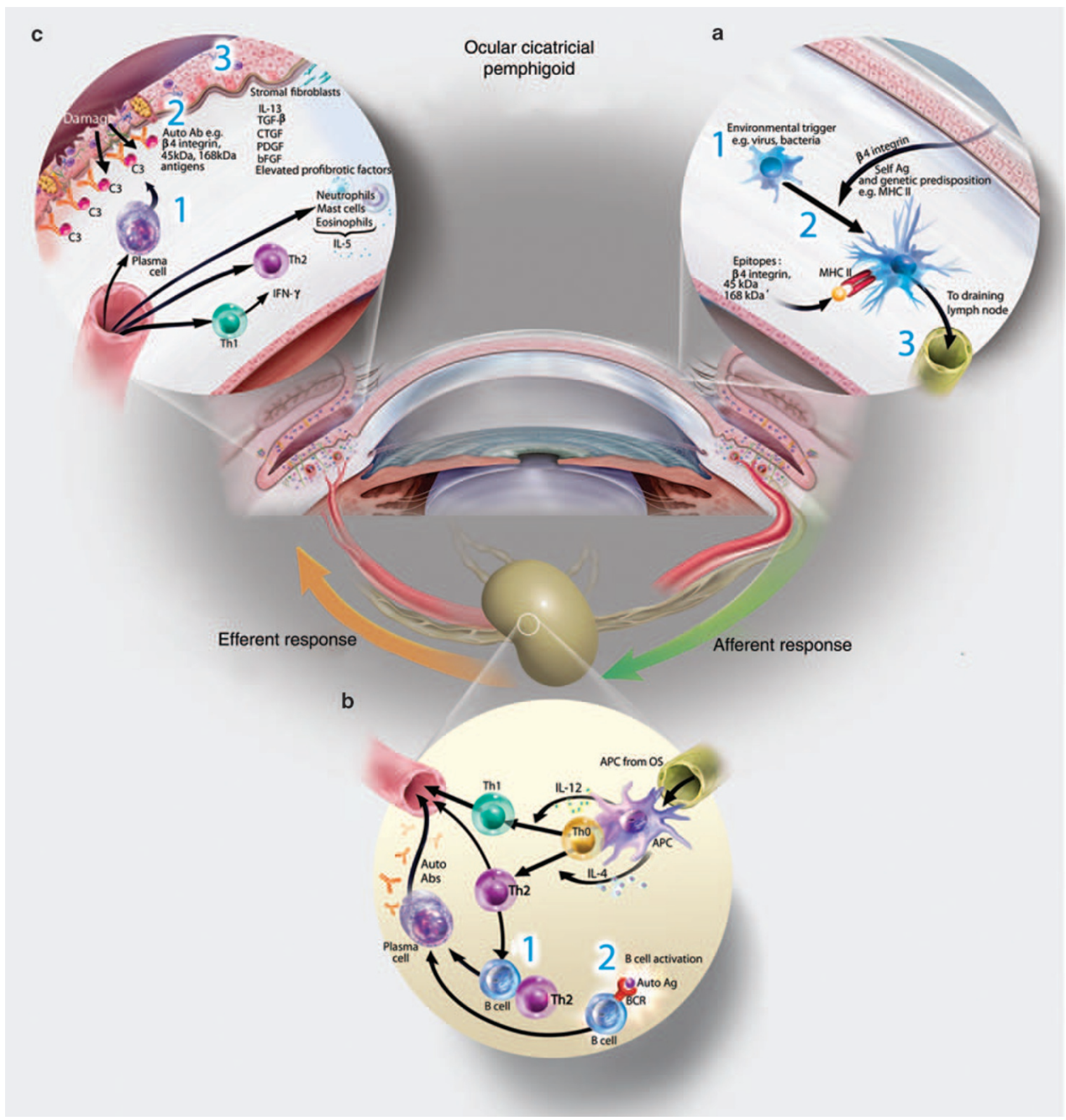

Figure 3 The immunopathogenesis of ocular cicatricial pemphigoid (OCP). (a) Afferent autoimmune response. (1) An environmental trigger, that is, stress to the ocular surface tissues in the context of genetic predisposition may initiate the events leading to autoimmunity. Induction of proinflammatory factors (cytokines, chemokines, and matrix metalloproteinases (MMPs)) sets the stage for (2) autoantigen (epitopes from example, $\beta 4$ integrin, putative 45 , and $168 \mathrm{kDa}$ antigens) presentation on major histocompatibility complex (MHC)II by APCs, upregulation of costimulatory molecules and (3) migration to the draining cervical lymph node. (b) Efferent activation of autoreactive B and T cells. (1) T cells may provide help to $B$ cells to undergo clonal expansion, somatic hypermutation, isotype switching, affinity maturation, and differentiation into autoantibody-secreting plasma cells. (2) Alternatively, autologous B-cell activation (e.g., TLR, BAFF signaling) may activate B cells (independently of T cells) to become autoantibody-secreting plasma cells. (c) Efferent effector function of autoantibodies, T cells, and cytokines. (1) Plasma cells secrete autoantibodies that (2) bind to their target self-antigens (e.g., $\beta 4$ integrin, and/or putative 45 and168 kDa antigens) to promote complement component 3 (C3) deposition and tissue destruction. (3) Overabundance of anti-inflammatory factors, namely transforming growth factor (TGF)- $\beta$, produced by ocular surface epithelial cells and innate effectors also contributes directly to pathology. Excessive TGF- $\beta$ favors production and accumulation of extracellular matrix proteins and overt tissue fibrosis. Interleukin (IL)-13 has recently been shown to be an important contributor to conjunctival fibrosis and inflammation in ocular cicatricial pemphigoid (OCP). Together these factors cause tissue scarring, which ultimately leads to blindness. 
syndrome. Thus, defective immune tolerance in the context of specific MHC haplotypes seems to dictate the development of primary vs. secondary Sjögren's-like phenotype in the NOD mouse.

Clinical and histopathological disease similar to that observed in primary Sjögren's syndrome can also be recapitulated in congenic C57BL/6 mice carrying non-MHC insulindependent diabetes ( $I d d$ )-associated genetic loci derived from NOD mice. Several elegant studies have shown that Sjögren's phenotype is dependent on a variety of genetically determined factors that may be related to immune and/or non-immune aspects of disease. ${ }^{81,83,85,86,90}$ Among the $19 \mathrm{Idd}$ regions indentified in the NOD mouse to date, two non-MHC regions (Idd3 and Idd5) are essential for Sjögren's syndrome-dependence; Idd 3 of chromosome 3, also designated autoimmune exocrinopathy 1 (Aec1), seems to have a hand in immune dysregulation, whereas Idd5 of chromosome 1 (Aec2) has a greater role in the non-immune features. ${ }^{83} \mathrm{Co}$-expression of $I d d 3$ from C57BL/ 6 and $I d d 5$ from C57BL/10 mice, in the context of the NOD mouse, was sufficient for disease; and transfer of both Aec1 and Aec2 into C57BL/6 mice resulted in accelerated onset of primary Sjögren's syndrome-like disease, supporting the possibility that both alleles act in concert during disease development. ${ }^{80}$ The C57BL/6.NOD-Aec1Aec2 mouse shows many clinical and histopathological similarities to human disease and is considered by many in the field to be an excellent model to study the underlying mechanisms involved in primary Sjögren's syndrome. ${ }^{80}$

\section{Graft vs. host disease}

Ocular surface graft vs. host disease (GVHD) is a local manifestation of a systemic autoimmune reaction that results after allogenic bone marrow transplantation in which donor lymphocytes recognize host cells as foreign. Ocular surface manifestations of GVHD include Dry Eye, keratoconjunctivitis sicca, pseudomembranous conjunctivitis, conjunctival fibrosis, lacrimal and meibomian gland disease, and corneal epithelial sloughing. ${ }^{91,92}$ The severity of ocular surface disease has been staged from 1 to 4 based on the extent of conjunctival inflammation, conjunctival scarring and corneal epithelial sloughing 91,92 GVHD may be acute (developing $<100$ days post-transplant) or chronic ( $>100$ days). Conjunctivitis is typically observed in acute GVHD, whereas Dry Eye and keratoconjunctivitis sicca are more commonly observed in chronic GVHD. Conjunctival immunopathology in acute GVHD shows T-cell infiltration within the conjunctival pseudomembranes and stroma. ${ }^{92,93}$ More specifically, conjunctival biopsies taken from patients with chronic GVHD showed a significant increase of: $\mathrm{CD} 3+$ and $\mathrm{CD} 14+$ cells in the epithelium, T lymphocytes $(\mathrm{CD} 3+, \mathrm{CD} 4+, \mathrm{CD} 8+)$ and CD14 cells in the stroma and very late antigen- 4 (VLA-4) and lymphocyte function associated antigen-1 (LFA-1) expression in the stroma. CD14 + cells were significantly increased both in the epithelium and in the stroma of patients with signs or symptoms of Dry Eye compared with patients without ocular involvement. ${ }^{94}$ In addition, those having keratoconjunctivitis sicca had significantly higher $\mathrm{CD} 4 / \mathrm{CD} 8$ ratios in the conjunctiva than those without. Inflammatory cytokines produced by the inflamed ocular mucosa and the infiltrating $T$ cells are considered to contribute to ocular surface disease. ${ }^{91}$ Acute GVHD is predominantly a Th1 reaction, whereas an increase in Th2 cytokines is observed in chronic GVHD; ${ }^{91} \mathrm{Th} 2$ cytokines promote activation of autoreactive $B$ cells and production of autoantibodies.

Therapy of ocular chronic GVHD is typically directed to the severe Dry Eye that accompanies disease. This includes topical anti-inflammatory agents, particularly cyclosporine $\mathrm{A}$ as well as autologous serum or plasma drops in the treatment of Dry Eye associated with graft vs. host disease. ${ }^{95,96}$

\section{Secondary ocular manifestations associated with systemic autoimmunity}

Ocular surface disease can occur with other systemic autoimmune conditions, predominantly rheumatoid arthritis. Approximately $50 \%$ of patients with rheumatoid arthritis develop Dry Eye (referred to as secondary Sjögren's syndrome). They may also develop episcleritis, scleritis, and central and marginal corneal inflammation and ulceration. The keratolysis developing in the central cornea in rheumatoid arthritis shows T-cell infiltration surrounding the ulcer and responds to topical cyclosporine. ${ }^{97}$ Secondary Sjögren's syndrome can also occur in SLE and systemic sclerosis. In addition, patients with psoriasis show inflammation within the lid, conjunctiva, and cornea. ${ }^{98}$ For example, corneal dryness accompanied by punctate keratitis and corneal melt may occur, and when the conjunctiva is affected, nonspecific conjunctivitis may heal with fibrosis and can result in symblepharon, entropion, and trichiasis. $^{98}$

\section{ETIOLOGY}

The etiologies of autoimmunity are largely unknown and an array of factors have been associated with the development ocular surface disease: (i) genetic factors (e.g., human leukocyte antigen (HLA) mutations, cytokine polymorphisms), (ii) environmental factors (e.g., trauma, stress, and pathogens), and (iii) hormone imbalance. Mutations in HLA and/or cytokines may put patients at a greater risk for activation of autoreactive lymphocytes, which are otherwise dampened by immunoregulatory mechanisms. Genetic predisposition based on HLA type and cytokine polymorphisms have been identified for Sjögren's syndrome, OCP, and Stevens-Johnson syndrome. The association between HLA and cytokine polymorphisms has been studied most extensively in Sjögren's syndrome, showing strong correlations with HLA-DR and -DQ alleles and in IL-10, IL-6, IL-1 receptor antagonist, IL-4 receptor- $\alpha$, tumor necrosis factor (TNF)- $\alpha$, IFN- $\gamma$, and TGF- $\beta 1$, respectively. ${ }^{99}$ HLA associations vary in different ethnic groups. For example, a strong association in Stevens-Johnson syndrome (induced by the anti-convulsant drug carbamazepine) and the HLA-B ${ }^{\star} 1502$ allele was noted in a Chinese population in Taiwan; this HLA type was found in $100 \%$ of patients, and correlated with a 900 times greater risk of disease. ${ }^{100}$ Patients with Stevens-Johnson syndrome also show cytokine polymorphisms in IL-4 receptor (SNP Gln551Arg) and IL-13 (SNP Arg110Gln). ${ }^{101}$ 
Environmental interplay has also been considered a major contributing factor to ocular surface autoimmunity. There is increasing recognition that activation of innate inflammatory systems by environmental stress can promote an adaptive immune response. In the case of Dry Eye, increased tear osmolarity has been recognized for decades and has been shown to activate proinflammatory signal transduction pathways. ${ }^{102-106}$ Local tissue injury has recently been suggested for initiating local and systemic autoimmunity, such as Sjögren's syndrome and SLE. Epidermal trauma was noted to activate IFN-responsive transcription factors that stimulated production of proinflammatory factors, including Th17 family cytokines. This process is normally regulated by Ro52, an E3 ligase that ubiquinates various members of the interferon regulatory factor family and inhibits IL-23 production, but progressed unchecked to autoimmunity in Ro50-/- mice. ${ }^{107}$

It is to be noted that viral infection has also been implicated as an initiating factor in Sjögren's syndrome and Stevens-Johnson syndrome. Certainly, the notion of a viral component in autoimmunity has been a common theme for decades. Molecular mimicry, that is, antigenic similarity between microbes and endogenous self-proteins, may provide a link between infection and autoimmunity at the ocular surface. ${ }^{108-110}$ Furthermore, viral products can directly stimulate nucleic acid-sensing Tolllike receptors (TLRs) to initiate a proinflammatory response, or they may damage cells causing exposure or release self-nucleic acids, which, in turn, may activate TLRs that promote the development of autoimmunity. ${ }^{111}$

Hormone imbalance may also contribute to autoimmunity. On the whole, females show a higher incidence in the vast majority of autoimmune diseases, and the prevalence of Dry Eye particularly when associated with Sjögren's syndrome is greater in women. ${ }^{112}$ Production of sex steroids in the gonads and adrenal glands, including estrogen and androgen decreases during menopause and aging and may contribute to immune activation. Androgens are recognized to suppress development of autoimmune reactions in the lacrimal glands, in part because of their ability to support epithelial expression of TGF- $\beta .{ }^{113}$

\section{IMMUNOPATHOGENESIS}

Immunopathogenesis of the diversity of ocular surface autoimmune diseases centers toward the common theme that environmental and/or microbial stress, combined with genetically predisposed factors stimulates autoreactive lymphocytes that perpetuate chronic tissue inflammation and dysfunction. Aberrant activation of the innate and adaptive immune response, which may occur when the innate immune system encounters excessive or atypical stimuli and/or immunoregulatory mechanisms are compromised, coordinates the autoimmune response. The innate immune system normally directs immunity to foreign invaders, but may also incite the initial events that allow self-antigen presentation in the context of the necessary costimulatory signals. In turn, autoreactive $T$ cells that escaped central tolerance are activated and targeted to the ocular surface tissues, or provide help to cognate B cells, leading to a direct pathogenic effect or autoantibody-mediated tissue destruction.

\section{"Aberrant" activation of the innate immune response}

General stress response. Stress to the ocular surface tissues is implicated with the immunopathgenesis of Dry Eye and Sjögren's syndrome, supported by data generated in humans and in animal models. General stress is sensed by Rho family GTPases (Rac, Rho, and cdc42) to activate mitogen-activated protein kinase pathways; mitogen-activated protein kinases activate Jun amino-terminal kinases/stress-activated protein kinases, which in turn modulate the activity of multiple transcription factors involved in cell growth, death, and the expression of inflammatory mediators. ${ }^{114}$ It is thought that stress-mediated proinflammatory cytokine production, combined with other etiologic factors, such as hormone imbalance and/or genetic abnormalities, provide the initial fuel that breaks immunological tolerance. Indeed, ultraviolet light, hyperosmolarity, and desiccation activate proinflammatory signal transduction pathways in the ocular surface epithelia of mice and humans. ${ }^{102-106}$ Exposure to increased osmolarity in vivo or in vitro activates mitogen-activated protein kinase pathways, particularly p38 and c-Jun, and NF-kB in the ocular surface epithelia. ${ }^{104,106}$ Desiccating and osmotic stress activate mitogen-activated protein kinase and NF-kB, stimulating production of a variety of inflammatory mediators by the ocular surface epithelium, including IL- $1 \beta, \mathrm{TNF}-\alpha$, T-cell-attracting chemokines (CCL5, CXCL9, and CXCL10), and number of MMPs (MMP1, 3, 9, 10, and 13). ${ }^{106,115,116}$ Jun amino-terminal kinase-2 also seems to have an essential role in desiccationinduced corneal epithelial disease by stimulating production of MMP1, MMP9, and cornified envelope precursors. ${ }^{117}$

\section{Pathogen-associated recognition receptors and autoimmunity.} The innate immune system has evolved to include several classes of pattern recognition receptors (PRRs), for example, membranebound TLRs and cytosolic inflammasome mediators, such as the NOD-like receptor family and absent in melanoma 2 (AIM2). PRRs recognize microbial products known as pathogen-associate molecular patterns. PRR signaling by epithelial cells, macrophages, DCs, and even B cells stimulates proinflammatory cytokine expression and APC activation. PRRs also sense endogenous danger signals (danger-associated molecular patterns) produced by damaged or dying cells. Importantly, danger-associated molecular patterns are produced under both infectious and sterile (without pathogenic challenge) conditions. Although these sensing mechanisms are indispensable for the health of the host, recent studies suggest that excessive activation of PRRs and/or stimulation by self-derived products may initiate proinflammatory events leading to autoimmunity. It is intriguing to speculate that this paradigm may also relate to the onset of ocular surface disease.

Excessive TLR activation in response to pathogens may provide an innate link to activation of autoreactive lymphocytes. Viral infection has been suggested as a contributing etiology in a wide-variety of autoimmune disease, including those that affect 
the ocular surface, for example, Epstein-Barr virus, human T-lymphotrophic virus. ${ }^{110,118}$ In addition to molecular mimicry, viral infection may also contribute to autoimmunity by promoting excessive TLR3 (dsRNA viruses), TLR7/8 (ssRNA viruses), or TLR9 (dsDNA viruses) stimulation. For example, latent viral infection with the sialotropic murine cytomegalovirus induces acute and chronic glandular disease resembling human Sjögren's syndrome. ${ }^{119}$ Similarly, polyI:C-mediated TLR3 activation within mouse salivary glands results in a rapid loss of glandular function. ${ }^{120}$ An association between abundant virus-sensing plasmacytoid DCs, their anti-viral type I IFN derivatives $($ IFN- $\alpha / \beta)$, and Sjögren's syndrome has also been noted. ${ }^{121,122}$ Furthermore, the combination of autoantibodies to RNA-binding proteins and intracellular material released by dying cells is capable of inducing IFN- $\alpha$ production in plasmacytoid DCs, ${ }^{121}$ suggesting sterile activation of TLRs by endogenous danger signals may contribute to the initiation of Sjögren's syndrome.

Endogenous danger signals may stimulate TLR and non-TLR PRRs to bridge the innate and adaptive autoimmune response by inducing cytokine production and activating APCs. Host DNA and/or RNA derived from dying (apoptotic or necrotic) or damaged cells can serve as danger-associated molecular patterns to activate the membrane-bound nucleic acid-sensing TLRs $(3,7,8$, and 9). This scenario would require to some extent localization of self-nucleic acids to the endosomal compartment in which TLRs interaction occurs, which is normally reserved for foreign nucleic acids. Cell death may be a main source of endogenous extracellular nucleic acid ${ }^{123,124}$ and the combination of nucleic acid concentration and location, coupled with immune complex formation (e.g., anti-nuclear antibodies-nucleic acid interactions) is implicated in the immunopathogenesis of SLE. ${ }^{125}$ Along these lines, uptake and concentration of self-derived nucleic acids by phagocytic immune cells (macrophages, DCs, and/or B cells) may provide a link to sterile TLR activation preceding the development of ocular surface autoimmunity. TLR-independent pathways may also contribute to aberrant nucleic acid sensing in the cytoplasm. For example, dsDNA-directed (e.g., immune complex), AIM2 inflammasome-mediated, IL- $1 \beta$ activation may provide a link to autoimmunity. ${ }^{126}$ However, whether or not elevated cell death observed in Sjögren's syndrome ${ }^{127}$ or Dry Eye, ${ }^{105}$ or intracellular redistribution of endogenous small cytoplasmic ribonucleoprotein complex, for example, SS-A/SSB factors (Ro52, Ro60 and La48) have a part in aberrant innate activation during ocular surface autoimmunity has not been established.

Proinflammatory factors. Induction of proinflammatory factors (cytokines, chemokines, and MMPs) is a hallmark of ocular surface autoimmunity (Figures 2a and 3a). Danger signals alter the pro- and anti-inflammatory cytokine balance within the ocular surface tissues and tears. The resulting proinflammatory milieu influences a diverse array of immunopathogenic mechanisms, including increased adhesion molecule expression on surface epithelial and vascular endothelial cells, activation, differentiation, and homing of innate (e.g., neutrophils, APCs) and adaptive (i.e., autroreactive $\mathrm{T}$ and $\mathrm{B}$ cells) effectors, and a direct pathogenic effect (e.g., cell death, hyperplasia, and fibrosis) on target tissues. In some cases, excessive production of anti-inflammatory factors can also directly contribute to tissue pathology.

Acute response cytokines, such as IL-1 $\alpha$, IL- $1 \beta$, TNF- $\alpha$, and IL-6 are elevated in patients with Dry Eye ${ }^{128}$ (Figure 2a), Sjögren's syndrome ${ }^{48} \mathrm{OCP}^{129}$ (Figure 3a) and Stevens-Johnson syndrome, ${ }^{130} \mathrm{IL}-1$ and TNF- $\alpha$ amplify inflammation on the ocular surface through processes that, for instance, increase adhesion molecule expression and activate APCs. Patients with either Dry Eye or Sjögren's syndrome show high-level intercellular adhesion molecule 1 (ICAM-1) expression on ocular surface endothelium ${ }^{131,132}$ and expression of costimulatory molecules, CD80, and CD86, and MHC class II on DCs. ${ }^{133}$ Activated DCs secrete additional proinflammatory factors (e.g., IL-6, IL-12, and B-cell activating factor (BAFF)) to potentiate and coordinate the autoimmune response. For instance, IL-12 and IL- 6 are involved in differentiation of Th 1 and Th17 T-cell subsets, respectively, ${ }^{134}$ and expression of BAFF is associated with B-cell activation. ${ }^{135}$ In addition to ICAM-1, increased expression of other trafficking molecules have also been observed; chemokine ligands, such as CCL3, CCL4, CCL5, CXCL9, and CXCL10, and the chemokine receptors CCR5 and CXCR3 are elevated in patients ${ }^{115}$ and in animal models. ${ }^{136}$ Increased levels of MMPs are also noted, with MMP-9 implicated in tear destabilization and corneal epithelial barrier disruption evident in Dry Eye. ${ }^{46,137,138}$ These acute inflammatory events breach the immunosuppressive environment of the ocular surface $e^{56,129,139}$ setting the stage for chronic autoimmunemediated pathology.

Overabundance of anti-inflammatory factors, namely TGF- $\beta$, produced by ocular surface epithelial cells and innate effectors can also contribute directly to pathology. Excessive TGF- $\beta$ modulates the relative abundance of extracellular matrix components and associated proteases (e.g., type I collagen and MMPs) to favor production and accumulation of extracellular matrix proteins and overt tissue fibrosis. ${ }^{140}$ This is evident in OCP patients, who show elevated levels of profibrotic factors (TGF- $\beta$, IL-13, basic fibroblast growth factor, and platelet-derived growth factor within conjunctival and stromal fibroblasts. ${ }^{65,67,141}$ Recently, IL-13 was shown to be an important contributor to conjunctival fibrosis and inflammation in OCP. IL-13 stimulates collagen lattice contraction and migration, and mutes MMP3 and 10 production. ${ }^{67}$ The investigators speculated that in this setting fibroblasts provide an additional link to autoreactive T-cell activation by assuming the role as APCs, as IL-13 also augmented expression of molecules required for T-cell costimulation (CD80, CD40), and antigen presentation (MHC class II) on fibroblasts. ${ }^{67}$

Autoantigen and antigen-presenting cells: a link to autoreactive Iymphocyte activation. APCs activated by a multitude of stimuli may show self-antigen to autoreactive $\mathrm{T}$ cells during the development and progression of autoimmunity. APCs are classified as professional (DCs, macrophages, B cells, and some epithelial cell types) or non-professional (e.g., fibroblasts), the latter does not constitutively express MHC required for 
antigen presentation. DCs are present in the healthy corneal stroma, but show negligible levels of costimulatory molecules and MHC class II in the central cornea. ${ }^{142}$ By contrast, acute inflammation, that is, danger signals, can stimulate significant increases in both the number of DCs, and in their activation status. ${ }^{133}$ Patients with Dry Eye or Sjögren's syndrome show enhanced expression of MHCII molecules (HLA-DR, HLA-DQ) in conjunctival biopsies, ${ }^{132}$ however, the relative expression on different APC subsets has not been evaluated. In addition, work in a laboratory model of Dry Eye disease showed significant overexpression of MHC class II by corneal CD11b + APC. ${ }^{143}$ More recently, B cells acting as APCs have been noted in autoimmune diseases, such as SLE $^{144,145}$ type 1 diabetes ${ }^{146}$ and rheumatoid arthritis. ${ }^{147}$ B cells are certainly capable of assuming the role of competent APCs; they are (i) found in the proper locations, (ii) able to internalize and present antigens on MHCII, (iii) upregulate necessary costimulatory molecules, and (iv) activate T cells. ${ }^{148}$ Indeed, B cells can prime T cells independently of other APCs. ${ }^{149} \mathrm{~B}$ cells are also proficient in capturing and concentrating small quantities of antigen through high affinity B-cell receptors; the quantity of antigen required is inversely proportional to B-cell receptor affinity. ${ }^{150}$ In the eye, $\mathrm{B}$ cells are present within the ocular surface tissues, ${ }^{151}$ thus it is possible that upregulation and/or exposure of autoantigen engender a larger repertoire of functional antigen-presenting B cells.

A number of autoantigens have been implicated with the initiation and development of ocular surface autoimmune disease based on the presence of autoantibodies in sera from patients, including Dry Eye (e.g., type 3 muscarinic acetylcholine receptor), Sjögren's syndrome (e.g., Ro 52 and $60 \mathrm{kDa}$, La $48 \mathrm{kDa}, \alpha$ fodrin) and OCP ( $\beta 4$ integrin). ${ }^{59,152,153}$ Aberrant expression and localization of endogenous self-antigens may provide the danger signals required to break peripheral tolerance and activate APCs with or without initial expression of cytokines. Apoptotic cell death and/or aberrant localization of autoantigens (e.g., Ro52, Ro60 and La48) may facilitate autoantigen processing and presentation, and given the fuel from acute stress or viral infection incite the initial stages of Sjögren's syndrome. ${ }^{154,155}$ Chronic muscarinic acetylcholine receptor stimulation causes proteolytic processing of autoantigens in endosomes; it is possible that these cryptic epitopes are secreted to the underlying interstitial space in which they are sampled by APCs. ${ }^{156}$ More recently, members of the Kallikrein family of proteins have been suggested in Dry Eye and Sjögren's syndrome. Tissue-specific expression of Kallikrein-13 and cognate serum autoantibodies are found in the IQI/Jic mouse model of Sjögren's syndrome. ${ }^{157}$ Sjögren's-like disease is also induced in rats after immunization with Kallikrein-1b22. ${ }^{158}$ Our group has also identified the epidermal growth factor-binding protein Kallikrein-13 as an autoantigen, which may be exposed to APCs when tear epidermal growth factor concentration decreases in eyes with lacrimal dysfunction. ${ }^{159}$ In this way, stress upregulates expression and exposes a higher burden of autoantigens, which may be captured by resident APCs on the ocular surface and/or leak through the draining lymphatics to be processed within the regional lymph nodes.
Stimulation of the adaptive immune response: activation and targeting of efferent autoreactive $T$ and $B$ cells

Autoimmune-mediated immunopathogenesis on the ocular surface can be attributed ultimately to chronic activation of autoreactive $\mathrm{T}$ and/or B cells. The preponderance of infiltrating $\mathrm{T}$ cells and autoantibodies within the ocular surface tissues of patients suffering from autoimmune disease and in animal models, coupled with the positive outcomes observed with T- and B-cell modulators, highlights the important role of these cells in driving immunopathogenesis. Emerging evidence suggests that distinct CD4 + T helper cell subsets (Th1, Th2, and Th17) have a cooperative role in directing the pathological consequences of ocular surface autoimmunity. From this perspective, Th1 and Th17 cells secrete specific cytokines that fuel the destructive inflammatory cycle; and, Th2 cells provide help to autoreactive $\mathrm{B}$ cells and promote clonal expansion, somatic hypermutation, isotype switching, affinity maturation, and plasma cell differentiation into autoantibody-secreting cells. It is also becoming clear that autoreactive B cells may be the first to break immune tolerance, independent of the innately activated autoreactive T cells.

Autoreactive T cells. Activation, differentiation, and homing of autoreactive T cells to the ocular surface tissues during Dry Eye and Sjögren's syndrome is controlled by the complex interplay between the factors and cells that comprise the local inflammatory environment (Figure 2). The subtle balance between cytokines and APCs dictates the fate of naïve CD4 + T cells harboring self-reactive TCRs (Figure $2 \mathbf{b}$ ). IL-12 present within the ocular surface tissues and produced by mature APCs, combined with IFN- $\gamma$, influences the activation and differentiation of autoreactive Th1 cells. ${ }^{134}$ By contrast, elevated IL-6 in the presence of TGF- $\beta$ and IL-23 skews differentiation toward Th17 cells. ${ }^{160,161}$ Appreciation for the importance of Th17 cells in autoimmunity is a relatively new concept. In the eye, the presence of abundant IL- 6 and IL-23 on the ocular surface and elevated expression of TGF- $\beta$ in patients with Dry Eye or Sjögren's syndrome provides a Th17-polarizing environment. ${ }^{46,52,55,162}$ There is some question as to whether or not Th17 differentiation and effector function require similar cytokines in humans and mice; nonetheless, a full repertoire of Th17-associated cytokines (e.g., IL-1, IL-6, IL-23, and TGF- $\beta$ ) are significantly elevated in Dry Eye and Sjögren's patients. ${ }^{52,55}$ Certainly, mice with ocular surface autoimmunity harbor Th17 cells. Not only have Th17 cells been identified, but pathogenic Th17 cells inhibit Treg-mediated suppression of pathogenic T cells during experimental Dry Eye. ${ }^{163}$ Furthermore, corneal epithelium-derived cytokines secreted after exposure to hyperosmotic, microbial, or inflammatory stimuli are able to induce Th17 differentiation. ${ }^{116}$ Therefore, ocular stress may lead to early induction of Th17 cells, which dysregulates Treg-dependent peripheral tolerance to facilitate activation of Th1 and Th17 cells.

Efferent trafficking of autoreactive $\mathrm{T}$ cells to the ocular surface tissues is widely thought to be directed by adhesion molecule and chemokine/chemokine receptor signaling. It is to be noted that ICAM-1 is highly expressed in patients with 
Dry Eye or Sjögren's syndrome and it is likely that diapedesis of activated CD $4+\mathrm{T}$ cells expressing the integrin LFA- 1 is facilitated through ICAM-1-LFA-1 interactions. ${ }^{132}$ CD $4+$ $\mathrm{T}$ cells from patients and in animal models also express chemokine receptors (e.g., CCR5 and CXCR3), and their cognate ligands (e.g., CCL5 and CXCL10) are expressed within the ocular surface tissues. ${ }^{115,136,164}$ Cytokines stimulate CCL5 and CXCL10 expression in human conjunctival epithelial cells, ${ }^{165}$ highlighting the importance of the acute inflammatory response in autoreactive T-cell homing. Indeed, Dry Eyespecific $\mathrm{T}$ cells show restricted trafficking to the ocular surface tissues after adoptive transfer into nude recipient mice. ${ }^{28}$ It is possible that differential expression of adhesion molecules and chemokines contribute to tissue-specific targeting of $\mathrm{T}$ cells among the spectrum of autoimmune diseases, for example, lacrimal glands vs. salivary glands. A handful of studies have shown the functional relevance of trafficking molecules during ocular surface inflammation. For example, blockade of the T-cell homing integrin, VLA-4, suppresses T-cell infiltration within the ocular surface tissues and clinical disease in a mouse model of Dry Eye. ${ }^{166}$ Similarly, neutralization of CCR2, which is critical for CD11b + monocyte recruitment, also attenuates murine Dry Eye disease. ${ }^{167}$ In addition, CCL5 blockade reduces lacrimal gland inflammation in NOD mice with a Sjögren's-like phenotype. ${ }^{168}$

Autoreactive Th 1 and Th17 cells potentiate the chronic immune response and have pathological consequences on the ocular surface (Figure 2c). Th1 cells and derivative cytokines, for example, IFN- $\gamma$ are present within the ocular surface tissues of patients with Dry Eye and Sjögren's syndrome and seem to correlate with disease severity. ${ }^{55,132,169}$ In a mouse model of Dry Eye, accumulation of infiltrating CD $4+\mathrm{T}$ cells is associated with increased cytokine production, epithelial cell apoptosis and decreased goblet cell density $28,40,41,136,170,171$ features similar to the pathology observed in human patients. Th1-derived IFN- $\gamma$ in Dry Eye mice alter mucins on corneal epithelial cells ${ }^{172}$ and cause tissue pathology; (i) elevated IFN$\gamma$ or (ii) exogenously added topical IFN- $\gamma$ in deficient mice correlate with reduced goblet cell density and/or squamous metaplasia. ${ }^{40,41}$ This effect is specific as goblet cell density is not affected in IFN- $\gamma$ knock-out mice. ${ }^{41}$ In addition, IFN- $\gamma$ serves a "gatekeeper" function and facilitates chronic inflammation by promoting diapedesis of targeted lymphocytes to the ocular surface. ${ }^{173}$ With respect to Th17 cells, increased numbers of IL-17 producing cells are found in the lacrimal functional unit and elevated IL-17 is present in the tears of Dry Eye mice. ${ }^{42,163}$ Early expression of IL- 17 within the ocular surface tissues may be derived from a subset of $\gamma \delta$ T cells, which have been shown to facilitate Th17 cell generation during autoimmune uveitis. ${ }^{174,175}$ During experimental Dry Eye, IL-17 neutralization decreases MMP3/9 expression and attenuates corneal epithelial barrier dysfunction. ${ }^{42}$ In an independent study, anti-IL-17 treatment reduced expansion of Th17 cells, and IL- 6 production by IL-17 target cells (epithelial, stromal, and immune cells), which coincided with restored Treg function and reduced disease severity. ${ }^{163}$ Taken together, data from patients and animal models suggests that stress sets the stage for immunoregulatory dysfunction, which is further exacerbated by activation of autoreactive Th17 cells; activated Th1 and Th17 cells home to the ocular surface in which they fuel the inflammatory cycle and cause epithelial cell metaplasia and tissue destruction.

Autoreactive B cells. Abnormal B-cell activity has an integral role in many of the autoimmune diseases discussed thus far, for example, Sjögren's syndrome, OCP. Historically, autoreactive $\mathrm{B}$ cells have been viewed as autoantibody-secreting precursors that are second-in-line after T-cell-dependent initiation of disease. As alluded, autoreactive B cells may also be the first to break immune tolerance, independent of previously activated $\mathrm{T}$ cells. B-cell dominant roles during the initiation of autoimmunity have been elegantly reviewed previously ${ }^{176-178}$ and include function as APCs and cytokine-secreting cells (e.g., IL-2, IL-12, TNF- $\alpha$, and IFN- $\gamma$ ), which modulate T cells and exert direct pathogenic effects. ${ }^{179}$ Aberrant TLR signaling and overexpression of the B-cell activation factor, BAFF, have also been implicated in autologous activation of autoreactive $B$ cells.

T-cell-independent activation of autoreactive B cells can be mediated by aberrant TLR signaling. For example, immune complexes containing DNA or RNA (IgG2a/chromatin) are sufficient to stimulate autoantibody production in B cells isolated from mice engineered to express AM14 rheumatoid factor (RF) (B cells in these mice respond to antichromatin IgG2a antibodies by producing RF antibodies); activation is dependent $\mathrm{B}$-cell receptor engagement and TLR7 and 9 signaling. ${ }^{180-182}$ In MRL.Fas ${ }^{\text {lpr }}$ SLE-prone mice (these mice are also susceptible to Sjögren'slike disease), TLR7 or TLR9 deficiency inhibits production of autoantibodies to RNA antigens ${ }^{183}$ and anti-dsDNA/anti-chromatin, ${ }^{184}$ respectively. Importantly, MRL/lpr mice-expressing AM14 RF B cells fully respond to IgG2a treatment by producing RF antibodies, whether or not mice are on a T-cell-competent or T-cell-deficient background. ${ }^{185}$ It is interesting to speculate that aberrant TLR signaling in Sjögren's patients, mediated by B-cell receptor uptake of extracellular complexes containing rheumatoid, SS-A-, SS-B-associated factors, induces activation of selfreactive $B$ cells. These autoreactive $B$ cells could then cooperate with helper $\mathrm{T}$ cells or function autonomously to become autoantibody-secreting plasmablasts.

Abnormal B-cell activity in Sjögren's syndrome has been associated with dysregulated production of BAFF. ${ }^{186} \mathrm{BAFF}$ is an important survival factor required for the normal development of B cells. ${ }^{187}$ However, when BAFF is overexpressed in transgenic mice, elevated levels of mature $B$ and $T$ effector cells, RFs, circulating immune complexes, and anti-DNA autoantibodies are associated with the development of spontaneous autoimmune nephritis ${ }^{188}$ and sialadenitis, ${ }^{189}$ similar to that observed in SLE and Sjögren's syndrome. Overexpression of BAFF results in accumulation of functional B cells within the follicular and marginal zone compartments of the spleen; ${ }^{190}$ however, mice lacking marginal zone B cells do not develop Sjögren's-like disease. ${ }^{191}$ Self-reactive B cells localized to the marginal zone pose an autoimmune threat to the host as these 
cells are exposed and respond robustly to T-cell-dependent and -independent stimuli and are potent activators of naïve CD4 + T cells. ${ }^{192,193}$ Sjögren's patients show high levels of BAFF that correlates with the presence of anti-SSA and anti-SSB autoantibodies. ${ }^{194}$ Aberrant BAFF expression is detected in epithelial cells, monocytes, T cell and B cells ${ }^{195-197}$ and in response to stimulation with proinflammatory cytokines, TLR agonists, and virus. ${ }^{198,199}$ Thus, in Sjögren's syndrome, elevated BAFF may impair B-cell self-tolerance in a way that (i) allows expansion and population of autoreactive $B$ cells to areas (e.g., marginal zone), (ii) in which they are exposed to a variety of potentially hazardous stimuli (e.g., antigenic immune complexes containing RNA, dsDNA, and TLR signaling), and (iii) become activated to assume a variety of functions (e.g., APCs, cytokinesecreting cells, and plasmablasts).

Whether by T-cell-dependent or -independent activation mechanisms the major pathological consequence of self-reactive B cells is autoantibody production. Indeed, passive transfer of IgG from animals or humans with Sjögren's syndrome, but not healthy controls, is sufficient to cause disease in recipient animals. ${ }^{200}$ Autoantibody deposition mediates tissue destruction through a variety of functions including activation of (i) innate cells (e.g., DCs, macrophages, and neutrophils) that bind to autoantibodies through Fc $\gamma$ receptors to release cytotoxic components (e.g., nitric oxide) or engulf targeted cells (e.g., during Sjögren's syndrome) and (ii) activation of the complement system, which results in phagocytosis or lysis of targeted cells (e.g., during OCP) (Figure 3c). Tissue damage releases more autoantigens, and when accompanied by enhanced proinflammatory cytokine production, the cycle is amplified to cause additional destruction and promote epitope spreading to a more diverse pool of target antigens.

\section{CONCLUSIONS}

A clearer picture of ocular surface autoimmunity is being painted from recent discoveries in animal models and humans to help explain the diversity among clinical diseases and within patient populations. Undoubtedly, autoreactive lymphocytes are the cornerstones of autoimmunity on the ocular surface. However, there is now a broader appreciation of when and how these cells become activated during the initial stages of disease. The complexity of environmental, microbial and endogenous stress, antigen localization, and genetic factors provide triggers underlying the immunological events that shape the outcome of ocular surface autoimmunity. For instance, Dry Eye seems to be a T-cell dominant form of disease, whereas subsets of patients with Sjögren's syndrome may represent a manifestation of either a T-cell dominant, B-cell dominant, or T-cell/B-cell cooperative form. In OCP, B cell activation leads to autoimmunity, and although $\mathrm{T}$ cells have been associated with human disease, their absolute necessity during initiation is not immediately apparent. These differences may also explain why some patients diagnosed with for example, Sjögren's syndrome, respond well to specific treatment paradigms (e.g., T-cell inhibition), whereas others do not. As always, caution must be taken in over interpreting findings from the variety of autoimmune models. With respect to human disease, some of the most difficult and fundamental questions are still unanswered: for example, What are the initiating stresses, genetic factors, antigens? Why are females generally more susceptible? Why do regulatory lymphocytes fail? For the latter, treatment strategies designed to attenuate disease (T-cell/B-cell inhibitors) may also significantly affect the regulatory subsets. Accordingly, therapeutic strategies designed to inhibit disease without compromising the protective immunoregulatory mechanisms are the wave of the future in treating autoimmunity on the ocular surface.

\section{ACKNOWLEDGMENTS}

This study has received funding from the National Institutes of Health (NIH RO1 EY018090).

\section{DISCLOSURE}

ME Stern and CS Schaumburg are employees of Allergan. JY Niederkorn, SC Pflugfelder, and M Calonge are consultants of Allergan.

(C) 2010 Society for Mucosal Immunology

\section{REFERENCES}

1. Stern, M.E. et al. The pathology of dry eye: the interaction between the ocular surface and lacrimal glands. Cornea 17, 584-589 (1998).

2. Beuerman, R., Mircheff, A.K., Pflugfelder, S.C. \& Stern, M.E. The lacrimal functional unit In Dry Eye and Ocular Surface Disorders (Pflugfelder, S.C., Beuerman, R.W. \& Stern, M.E., eds) 11-39 (Marchel Dekker, New York, 2004).

3. Muller, L.J., Marfurt, C.F., Kruse, F. \& Tervo, T.M. Corneal nerves: structure, contents and function. Exp. Eye Res. 76, 521-542 (2003).

4. Krupin, T., Cross, D.A. \& Becker, B. Decreased basal tear production associated with general anesthesia. Arch. Ophthalmol. 95, 107-108 (1977).

5. Semana, G., Gausling, R., Jackson, R.A. \& Hafler, D.A. T cell autoreactivity to proinsulin epitopes in diabetic patients and healthy subjects. J. Autoimmun. 12, 259-267 (1999).

6. Knop, E. \& Knop, N. Lacrimal drainage-associated lymphoid tissue (LDALT): a part of the human mucosal immune system. Invest. Ophthalmol. Vis. Sci. 42, 566-574 (2001).

7. Knop, N. \& Knop, E. Conjunctiva-associated lymphoid tissue in the human eye. Invest. Ophthalmol. Vis. Sci. 41, 1270-1279 (2000).

8. Gupta, A. et al. Transforming growth factor beta-1 and beta-2 in human tear fluid. Curr. Eye Res. 15, 605-614 (1996).

9. Shen, L., Barabino, S., Taylor, A.W. \& Dana, M.R. Effect of the ocular microenvironment in regulating corneal dendritic cell maturation. Arch. Ophthalmol. 125, 908-915 (2007).

10. Gorelik, L. \& Flavell, R.A. Abrogation of TGFbeta signaling in T cells leads to spontaneous T cell differentiation and autoimmune disease. Immunity 12, 171-181 (2000).

11. Horwitz, D.A., Zheng, S.G. \& Gray, J.D. The role of the combination of IL-2 and TGF-beta or IL-10 in the generation and function of CD4+ CD25+ and CD8+ regulatory T cell subsets. J. Leukoc. Biol. 74, 471-478 (2003).

12. Chen, W. et al. Conversion of peripheral CD4+. J. Exp. Med. 198, 1875-1886 (2003).

13. Hannum, C.H. et al. Interleukin-1 receptor antagonist activity of a human interleukin-1 inhibitor. Nature 343, 336-340 (1990).

14. Kennedy, M.C. et al. Novel production of interleukin-1 receptor antagonist peptides in normal human cornea. J. Clin. Invest 95, 82-88 (1995).

15. Szliter, E.A., Lighvani, S., Barrett, R.P. \& Hazlett, L.D. Vasoactive intestinal peptide balances pro- and anti-inflammatory cytokines in the Pseudomonas aeruginosa-infected cornea and protects against corneal perforation. J. Immunol. 178, 1105-1114 (2007).

16. Schirra, F., Seitz, B., Knop, N. \& Knop, E. Sex hormones and dry eye. Ophthalmologe 106, 988-994 (2009).

17. Cursiefen, C. et al. Nonvascular VEGF receptor 3 expression by corneal epithelium maintains avascularity and vision. Proc. Natl. Acad. Sci. USA 103, 11405-11410 (2006). 
18. Ambati, B.K. et al. Corneal avascularity is due to soluble VEGF receptor-1. Nature 443, 993-997 (2006).

19. Hori, J. et al. B7-H1-induced apoptosis as a mechanism of immune privilege of corneal allografts. J. Immunol. 177, 5928-5935 (2006).

20. Hori, J. Role of B7-H1 in immune privilege of the eye. J. Nippon Med. Sch 75, 56-57 (2008).

21. Shen, L., Jin, Y., Freeman, G.J., Sharpe, A.H. \& Dana, M.R. The function of donor versus recipient programmed death-ligand 1 in corneal allograft survival. J. Immunol. 179, 3672-3679 (2007).

22. El, A.J. et al. Programmed death-ligand 1 (PD-L1) regulates T cell chemotaxis in Dry Eye-associated corneal inflammation. Invest. Ophthalmol. Vis. Sci. (2009) (Epub ahead of print).

23. Chan, J.H., Amankwah, R., Robins, R.A., Gray, T. \& Dua, H.S. Kinetics of immune cell migration at the human ocular surface. Br. J. Ophthalmol. 92, 970-975 (2008).

24. Sacks, E.H., Wieczorek, R., Jakobiec, F.A. \& Knowles, D.M. Lymphocytic subpopulations in the normal human conjunctiva. A monoclonal antibody study. Ophthalmology 93, 1276-1283 (1986).

25. Poussier, P., Ning, T., Banerjee, D. \& Julius, M. A unique subset of selfspecific intraintestinal T cells maintains gut integrity. J. Exp. Med. 195, 1491-1497 (2002)

26. Streilein, J.W. \& Niederkorn, J.Y. Characterization of the suppressor cell(s) responsible for anterior chamber-associated immune deviation (ACAID) induced in BALB/c mice by P815 cells. J. Immunol. 134, 1381-1387 (1985)

27. Wilbanks, G.A. \& Streilein, J.W. Characterization of suppressor cells in anterior chamber-associated immune deviation (ACAID) induced by soluble antigen. Evidence of two functionally and phenotypically distinct T-suppressor cell populations. Immunology 71, 383-389 (1990).

28. Niederkorn, J.Y. et al. Desiccating stress induces T cell-mediated Sjogren's syndrome-like lacrimal keratoconjunctivitis. J. Immunol. 176, 3950-3957 (2006)

29. Siemasko, K.F. et al. In vitro expanded CD4+CD25+Foxp3+ regulatory T cells maintain a normal phenotype and suppress immune-mediated ocular surface inflammation. Invest. Ophthalmol. Vis. Sci. 19, 5434-5440 (2008)

30. Pflugfelder, S.C. Prevalence, burden, and pharmacoeconomics of dry eye disease. Am. J. Manag. Care 14, S102-S106 (2008).

31. Mertzanis, P. et al. The relative burden of dry eye in patients' lives: comparisons to a U.S. normative sample. Invest Ophthalmol. Vis. Sci. 46, 46-50 (2005).

32. The epidemiology of dry eye disease: report of the Epidemiology Subcommittee of the International Dry Eye WorkShop. Ocul. Surf. 5, 93-107 (2007)

33. Management and therapy of dry eye disease: report of the Management and Therapy Subcommittee of the International Dry Eye WorkShop (2007). Ocul. Surf. 5, 163-178 (2007)

34. Gao, J., Gelber-Schwalb, T.A., Addeo, J.V. \& Stern, M.E. Apoptosis in the lacrimal gland and conjunctiva of dry eye dogs. Adv. Exp. Med. Biol. 438, 453-460 (1998).

35. Hicks, S.J., Carrington, S.D., Kaswan, R.L., Stern, M.E. \& Corfield, A.P. Secreted and membrane bound ocular mucins from normal and dry eye dogs. Biochem. Soc. Trans. 23, 537S (1995)

36. Hicks, S.J. et al. Biochemical analysis of ocular surface mucin abnormalities in dry eye: the canine model. Exp. Eye Res. 67, 709-718 (1998).

37. Berdoulay, A., English, R.V. \& Nadelstein, B. Effect of topical $0.02 \%$ tacrolimus aqueous suspension on tear production in dogs with keratoconjunctivitis sicca. Vet. Ophthalmol. 8, 225-232 (2005).

38. Gao, J., Schwalb, T.A., Addeo, J.V., Ghosn, C.R. \& Stern, M.E. The role of apoptosis in the pathogenesis of canine keratoconjunctivitis sicca: the effect of topical cyclosporin A therapy. Cornea 17, 654-663 (1998).

39. Schrader, S., Mircheff, A.K. \& Geerling, G. Animal models of dry eye. Dev. Ophthalmol. 41, 298-312 (2008).

40. de Paiva, C.S. et al. IFN- $\gamma$ promotes goblet cell loss in response to desiccating ocular stress. Invest. Ophthalmol. Vis. Sci. 47, E-Abstract 5579 (2006).

41. de Paiva, C.S. et al. Dry Eye-induced conjunctival epithelial squamous metaplasia is modulated by interferon-\{gamma\}. Invest. Ophthalmol. Vis. Sci. 48, 2553-2560 (2007).

42. de Paiva, C.S. et al. IL-17 disrupts corneal barrier following desiccating stress. Mucosal. Immunol. 2, 243-253 (2009).
43. Mircheff, A.K. et al. Mucosal immunity and self-tolerance in the ocular surface system. Ocul. Surf. 3, 182-192 (2005).

44. Pflugfelder, S.C. et al. Epstein-Barr virus and the lacrimal gland pathology of Sjogren's syndrome. Am. J. Pathol. 143, 49-64 (1993).

45. Triantafyllopoulou, A. \& Moutsopoulos, H. Persistent viral infection in primary Sjogren's syndrome: review and perspectives. Clin. Rev. Allergy Immunol. 32, 210-214 (2007).

46. Chotikavanich, S. et al. Production and activity of matrix metalloproteinase- 9 on the ocular surface increase in dysfunctional tear syndrome. Invest. Ophthalmol. Vis. Sci. 50, 3203-3209 (2009).

47. Jones, D. et al. Evaluation of cytokine expression in the c onjunctival epithelia of Sjogren's syndrome patients. Invest. Ophthalmo/ 35, 3493-3504 (1994).

48. Pflugfelder, S.C., Jones, D., Ji, Z., Afonso, A. \& Monroy, D. Altered cytokine balance in the tear fluid and conjunctiva of patients with Sjogren's syndrome keratoconjunctivitis sicca. Curr. Eye Res. 19, 201-211 (1999).

49. Lane, H.C., Callihan, T.R., Jaffe, E.S., Fauci, A.S. \& Moutsopoulos, H.M. Presence of intracytoplasmic lgG in the lymphocytic infiltrates of the minor salivary glands of patients with primary Sjogren's syndrome. Clin. Exp. Rheumatol. 1, 237-239 (1983).

50. Pepose, J.S., Akata, R.F., Pflugfelder, S.C. \& Voigt, W. Mononuclear cell phenotypes and immunoglobulin gene rearrangements in lacrimal gland biopsies from patients with Sjogren's syndrome. Ophthalmology 97, 1599-1605 (1990).

51. Skopouli, F.N. et al. T cell subpopulations in the labial minor salivary gland histopathologic lesion of Sjogren's syndrome. J. Rheumatol. 18, 210-214 (1991).

52. Katsifis, G.E., Rekka, S., Moutsopoulos, N.M., Pillemer, S. \& Wahl, S.M. Systemic and local interleukin-17 and linked cytokines associated with Sjogren's syndrome immunopathogenesis. Am. J. Pathol. 175, 1167-1177 (2009).

53. Zoukhri, D., Macari, E. \& Kublin, C.L. A single injection of interleukin-1 induces reversible aqueous-tear deficiency, lacrimal gland inflammation, and acinar and ductal cell proliferation. Exp. Eye Res. 84, 894-904 (2007).

54. Bolland, S. \& Garcia-Sastre, A. Vicious circle: systemic autoreactivity in Ro52/TRIM21-deficient mice. J. Exp. Med. 206, 1647-1651 (2009).

55. Lam, H. et al. Tear cytokine profiles in dysfunctional tear syndrome. Am. J. Ophthalmol. 147, 198-205 (2009).

56. Solomon, A. et al. Pro- and anti-inflammatory forms of interleukin-1 in the tear fluid and conjunctiva of patients with dry-eye disease. Invest. Ophthalmol. Vis. Sci. 42, 2283-2292 (2001).

57. Pijpe, J. et al. Clinical and histologic evidence of salivary gland restoration supports the efficacy of rituximab treatment in Sjogren's syndrome. Arthritis Rheum. 60, 3251-3256 (2009).

58. Seror, R. et al. Tolerance and efficacy of rituximab and changes in serum $\mathrm{B}$ cell biomarkers in patients with systemic complications of primary Sjogren's syndrome. Ann. Rheum. Dis. 66, 351-357 (2007).

59. Chan, L.S. et al. The first international consensus on mucous membrane pemphigoid: definition, diagnostic criteria, pathogenic factors, medical treatment, and prognostic indicators. Arch. Dermatol. 138, 370-379 (2002).

60. Schumann, T., Schmidt, E., Booken, N., Goerdt, S. \& Goebeler, M. Successful treatment of mucous membrane pemphigoid with the antiCD-20 antibody rituximab. Acta. Derm. Venereol. 89, 101-102 (2009).

61. Ahmed, M., Zein, G., Khawaja, F. \& Foster, C.S. Ocular cicatricial pemphigoid: pathogenesis, diagnosis and treatment. Prog. Retin. Eye Res. 23, 579-592 (2004).

62. Bernauer, W., Wright, P., Dart, J.K., Leonard, J.N. \& Lightman, S. The conjunctiva in acute and chronic mucous membrane pemphigoid. An immunohistochemical analysis. Ophthalmology 100, 339-346 (1993).

63. Rice, B.A. \& Foster, C.S. Immunopathology of cicatricial pemphigoid affecting the conjunctiva. Ophthalmology 97, 1476-1483 (1990).

64. Sacks, E.H. et al. Immunophenotypic analysis of the inflammatory infiltrate in ocular cicatricial pemphigoid. Further evidence for a $T$ cellmediated disease. Ophthalmology 96, 236-243 (1989).

65. Elder, M.J., Dart, J.K. \& Lightman, S. Conjunctival fibrosis in ocular cicatricial pemphigoid--the role of cytokines. Exp. Eye Res. 65, 165-176 (1997).

66. Razzaque, M.S., Foster, C.S. \& Ahmed, A.R. Role of connective tissue growth factor in the pathogenesis of conjunctival scarring in ocular cicatricial pemphigoid. Invest. Ophthalmol Vis. Sci. 44, 1998-2003 (2003). 
67. Saw, V.P. et al. Conjunctival interleukin-13 expression in mucous membrane pemphigoid and functional effects of interleukin-13 on conjunctival fibroblasts in vitro. Am. J. Pathol. 175, 2406-2415 (2009).

68. Hazin, R., Ibrahimi, O.A., Hazin, M.I. \& Kimyai-Asadi, A. StevensJohnson syndrome: pathogenesis, diagnosis, and management. Ann. Med. 40, 129-138 (2008).

69. Caproni, M. et al. The CD40/CD40 ligand system is expressed in the cutaneous lesions of erythema multiforme and Stevens-Johnson syndrome/toxic epidermal necrolysis spectrum. Br. J. Dermatol. 154, 319-324 (2006).

70. de Paiva, C.S. et al. Cleavage of functional IL-2 receptor alpha chain (CD25) from murine corneal and conjunctival epithelia by MMP-9. J. Inflamm. (Lond) 6, 31 (2009).

71. French, L.E., Trent, J.T. \& Kerdel, F.A. Use of intravenous immunoglobulin in toxic epidermal necrolysis and Stevens-Johnson syndrome: our current understanding. Int. Immunopharmacol. 6, 543-549 (2006).

72. LeCleach, L. et al. Blister fluid T lymphocytes during toxic epidermal necrolysis are functional cytotoxic cells which express human natural killer (NK) inhibitory receptors. Clin. Exp. Immunol. 119, 225-230 (2000).

73. Borchers, A.T., Lee, J.L., Naguwa, S.M., Cheema, G.S. \& Gershwin, M.E. Stevens-Johnson syndrome and toxic epidermal necrolysis. Autoimmun. Rev. 7, 598-605 (2008).

74. Shay, E. et al. Amniotic membrane transplantation as a new therapy for the acute ocular manifestations of Stevens-Johnson syndrome and toxic epidermal necrolysis. Surv. Ophthalmol 54, 686-696 (2009).

75. Wall, V., Yen, M.T., Yang, M.C., Huang, A.J. \& Pflugfelder, S.C. Management of the late ocular sequelae of Stevens-Johnson syndrome. Ocul. Surf. 1, 192-201 (2003).

76. Makino, S. et al. Breeding of a non-obese, diabetic strain of mice. Jikken Dobutsu 29, 1-13 (1980).

77. Silveira, P.A. \& Baxter, A.G. The NOD mouse as a model of SLE. Autoimmunity 34, 53-64 (2001).

78. Many, M.C., Maniratunga, S. \& Denef, J.F. The non-obese diabetic (NOD) mouse: an animal model for autoimmune thyroiditis. Exp. Clin. Endocrinol. Diabetes 104 (Suppl 3), 17-20 (1996).

79. Humphreys-Beher, M.G., Hu, Y., Nakagawa, Y., Wang, P.L. \& Purushotham, K.R. Utilization of the non-obese diabetic (NOD) mouse as an animal model for the study of secondary Sjogren's syndrome. Adv. Exp. Med. Biol. 350, 631-636 (1994).

80. Cha, S., Nagashima, H., Brown, V.B., Peck, A.B. \& Humphreys-Beher, M.G. Two NOD Idd-associated intervals contribute synergistically to the development of autoimmune exocrinopathy (Sjogren's syndrome) on a healthy murine background. Arthritis Rheum. 46, 1390-1398 (2002).

81. Robinson, C.P., Yamamoto, H., Peck, A.B. \& Humphreys-Beher, M.G. Genetically programmed development of salivary gland abnormalities in the NOD (nonobese diabetic)-scid mouse in the absence of detectable Iymphocytic infiltration: a potential trigger for sialoadenitis of NOD mice. Clin. Immunol. Immunopathol. 79, 50-59 (1996).

82. Robinson, C.P. et al. A novel NOD-derived murine model of primary Sjogren's syndrome. Arthritis Rheum. 41, 150-156 (1998).

83. Brayer, J. et al. Alleles from chromosomes 1 and 3 of NOD mice combine to influence Sjogren's syndrome-like autoimmune exocrinopathy. J. Rheumatol. 27, 1896-1904 (2000).

84. Kikutani, H. \& Makino, S. The murine autoimmune diabetes model: NOD and related strains. Adv. Immunol. 51, 285-322 (1992).

85. Cha, S. et al. Abnormal organogenesis in salivary gland development may initiate adult onset of autoimmune exocrinopathy. Exp. Clin. Immunogenet. 18, 143-160 (2001).

86. Hu, Y., Nakagawa, Y., Purushotham, K.R. \& Humphreys-Beher, M.G. Functional changes in salivary glands of autoimmune disease-prone NOD mice. Am. J. Physiol 263, E607-E614 (1992).

87. Humphreys-Beher, M.G. et al. Characterization of antinuclear autoantibodies present in the serum from nonobese diabetic (NOD) mice. Clin. Immunol. Immunopathol. 68, 350-356 (1993).

88. Yanagi, K. et al. Anti-120-kDa alpha-fodrin immune response with Th1cytokine profile in the NOD mouse model of Sjogren's syndrome. Eur. J. Immunol. 28, 3336-3345 (1998).

89. Yamano, S., Atkinson, J.C., Baum, B.J. \& Fox, P.C. Salivary gland cytokine expression in NOD and normal BALB/c mice. Clin. Immunol. 92, 265-275 (1999).

90. Yamachika, S. et al. Excessive synthesis of matrix metalloproteinases in exocrine tissues of NOD mouse models for Sjogren's syndrome. J. Rheumatol. 25, 2371-2380 (1998).
91. Kim, S.K. Ocular graft vs. host disease. Ocul. Surf. 3, S177-S179 (2005).

92. Lew, J. \& Smith, J.A. Mucosal graft-vs-host disease. Oral Dis. 13, 519-529 (2007).

93. Saito, T. et al. Ocular manifestation of acute graft-versus-host disease after allogeneic peripheral blood stem cell transplantation. Int. J. Hematol. 75, 332-334 (2002).

94. Rojas, B. et al. Cell populations and adhesion molecules expression in conjunctiva before and after bone marrow transplantation. Exp. Eye Res 81, 313-325 (2005).

95. Ogawa, Y. et al. Autologous serum eye drops for the treatment of severe dry eye in patients with chronic graft-versus-host disease. Bone Marrow Transplant. 31, 579-583 (2003).

96. Rao, S.N. \& Rao, R.D. Efficacy of topical cyclosporine $0.05 \%$ in the treatment of dry eye associated with graft versus host disease. Cornea 25, 674-678 (2006).

97. Kervick, G.N. et al. Paracentral rheumatoid corneal ulceration. Clinical features and cyclosporine therapy. Ophthalmology 99, 80-88 (1992).

98. Eustace, P. \& Pierse, D. Ocular psoriasis. Br. J. Ophthalmo/ 54, 810-813 (1970).

99. Cobb, B.L., Lessard, C.J., Harley, J.B. \& Moser, K.L. Genes and Sjogren's syndrome. Rheum. Dis. Clin. North Am. 34, 847-68, vii (2008).

100. Chung, W.H. et al. Medical genetics: a marker for Stevens-Johnson syndrome. Nature 428, 486 (2004).

101. Ueta, M. et al. Association of combined IL-13/IL-4R signaling pathway gene polymorphism with Stevens-Johnson syndrome accompanied by ocular surface complications. Invest Ophthalmol Vis. Sci. 49, 1809-1813 (2008).

102. Corrales, R.M. et al. Desiccating stress stimulates expression of matrix metalloproteinases by the corneal epithelium. Invest Ophthalmol. Vis. Sci. 47, 3293-3302 (2006).

103. Li, D.Q., Chen, Z., Song, X.J., Luo, L. \& Pflugfelder, S.C. Stimulation of matrix metalloproteinases by hyperosmolarity via a JNK pathway in human corneal epithelial cells. Invest. Ophthalmol Vis. Sci. 45, 4302-4311 (2004).

104. Luo, L., Li, D.Q., Corrales, R.M. \& Pflugfelder, S.C. Hyperosmolar saline is a proinflammatory stress on the mouse ocular surface. Eye Contact Lens 31, 186-93 (2005).

105. Luo, L., Li, D.Q. \& Pflugfelder, S.C. Hyperosmolarity-induced apoptosis in human corneal epithelial cells is mediated by cytochrome $c$ and MAPK pathways. Cornea 26, 452-460 (2007).

106. Luo, L. et al. Experimental dry eye stimulates production of inflammatory cytokines and MMP-9 and activates MAPK signaling pathways on the ocular surface. Invest. Ophthalmol Vis. Sci. 45, 4293-4301 (2004).

107. Espinosa, A. et al. Loss of the lupus autoantigen Ro52/Trim21 induces tissue inflammation and systemic autoimmunity by disregulating the IL-23-Th17 pathway. J. Exp. Med. 206, 1661-1671 (2009).

108. Kohsaka, H. et al. Fine epitope mapping of the human SS-B/La protein. Identification of a distinct autoepitope homologous to a viral gag polyprotein. J. Clin. Invest 85, 1566-1574 (1990).

109. Hishikawa, T. et al. Detection of antibodies to a recombinant gag protein derived from human endogenous retrovirus clone 4-1 in autoimmune diseases. Viral. Immunol. 10, 137-147 (1997).

110. Toussirot, E. \& Roudier, J. Epstein-Barr virus in autoimmune diseases. Best. Pract. Res. Clin. Rheumatol. 22, 883-896 (2008).

111. Pflugfelder, S.C. \& Stern, M.E. Immunoregulation on the ocular surface: 2nd Cullen Symposium. Ocul. Surf. 7, 67-77 (2009).

112. Versura, P. \& Campos, E.C. Menopause and dry eye. A possible relationship. Gynecol. Endocrinol. 20, 289-298 (2005).

113. Rocha, E.M. et al. Presence and testosterone influence on the levels of anti- and pro-inflammatory cytokines in lacrimal tissues of a mouse model of Sjogren's syndrome. Adv. Exp. Med. Biol. 438, :485-491 (1998).

114. Johnson, G.L. \& Nakamura, K. The c-jun kinase/stress-activated pathway: regulation, function and role in human disease. Biochim. Biophys. Acta 1773, 1341-1348 (2007).

115. Yoon, K.C. et al. Expression of CXCL9, CXCL10, and CXCL11, and CXCR3 in the tear film and ocular surface of patients with Dry Eye syndrome. Invest. Ophthalmol. Vis. Sci. 51, 643-650 (2009).

116. Zheng, X. et al. Induction of Th17 differentiation by corneal epithelialderived cytokines. J. Cell Physiol 222, 95-102 (2010).

117. de Paiva, C.S. et al. Essential role for C-Jun N-terminal kinase 2 in corneal epithelial response to desiccating stress. Arch. Ophthalmol. 127, 1625-1631 (2009). 
118. Green, J.E., Hinrichs, S.H., Vogel, J. \& Jay, G. Exocrinopathy resembling Sjogren's syndrome in HTLV-1 tax transgenic mice. Nature 341, 72-74 (1989).

119. Ohyama, Y. et al. Severe focal sialadenitis and dacryoadenitis in NZM2328 mice induced by MCMV: a novel model for human Sjogren's syndrome. J. Immunol. 177, 7391-7397 (2006).

120. Deshmukh, U.S., Nandula, S.R., Thimmalapura, P.R., Scindia, Y.M. \& Bagavant, $H$. Activation of innate immune responses through Toll-like receptor 3 causes a rapid loss of salivary gland function. J. Oral Pathol. Med. 38, 42-47 (2009).

121. Bave, U. et al. Activation of the type I interferon system in primary Sjogren's syndrome: a possible etiopathogenic mechanism. Arthritis Rheum. 52, 1185-1195 (2005)

122. Gottenberg, J.E. et al. Activation of IFN pathways and plasmacytoid dendritic cell recruitment in target organs of primary Sjogren's syndrome. Proc. Natl. Acad. Sci. USA 103, 2770-2775 (2006).

123. Choi, J.J., Reich, C.F. III \& Pisetsky, D.S. Release of DNA from dead and dying lymphocyte and monocyte cell lines in vitro. Scand. J. Immunol. 60, 159-166 (2004).

124. Tran, T.T., Groben, P. \& Pisetsky, D.S. The release of DNA into the plasma of mice following hepatic cell death by apoptosis and necrosis. Biomarkers 13, 184-200 (2008).

125. Su, K.Y. \& Pisetsky, D.S. The role of extracellular DNA in autoimmunity in SLE. Scand. J. Immunol. 70, 175-183 (2009).

126. Burckstummer, T. et al. An orthogonal proteomic-genomic screen identifies AIM2 as a cytoplasmic DNA sensor for the inflammasome. Nat. Immunol. 10, 266-272 (2009).

127. Manganelli, P. \& Fietta, P. Apoptosis and Sjogren syndrome. Semin. Arthritis Rheum. 33, 49-65 (2003).

128. Turner, K. et al. Interleukin-6 levels in the conjunctival epithelium of patients with dry eye disease treated with cyclosporine ophthalmic emulsion. Cornea 19, 492-496 (2000).

129. Kumari, S., Bhol, K.C., Rehman, F., Foster, C.S. \& Ahmed, A.R Interleukin 1 components in cicatricial pemphigoid. Role in intravenous immunoglobulin therapy. Cytokine 14, 218-224 (2001).

130. Caproni, M. et al. Expression of cytokines and chemokine receptors in the cutaneous lesions of erythema multiforme and Stevens-Johnson syndrome/ toxic epidermal necrolysis. Br. J. Dermatol. 155, 722-728 (2006).

131. Pisella, P.J. et al. Flow cytometric analysis of conjunctival epithelium in ocular rosacea and keratoconjunctivitis sicca. Ophthalmology 107, 1841-1849 (2000).

132. Stern, M.E. et al. Conjunctival T-cell subpopulations in Sjogren's and non-Sjogren's patients with dry eye. Invest. Ophthalmol Vis Sci 43, 2609-2614 (2002).

133. Hamrah, P., Liu, Y., Zhang, Q. \& Dana, M.R. Alterations in corneal stromal dendritic cell phenotype and distribution in inflammation. Arch. Ophthalmol. 121, 1132-1140 (2003).

134. Zhou, L., Chong, M.M. \& Littman, D.R. Plasticity of CD4+ T cell lineage differentiation. Immunity 30, 646-655 (2009).

135. Mackay, F., Silveira, P.A. \& Brink, R. B cells and the BAFF/APRIL axis: fast-forward on autoimmunity and signaling. Curr. Opin. Immunol. 19, 327-336 (2007).

136. Yoon, K.C. et al. Expression of th-1 chemokines and chemokine receptors on the ocular surface of C57BL/6 mice: effects of desiccating stress. Invest Ophthalmol. Vis. Sci. 48, 2561-2569 (2007).

137. Li, D.Q. et al. Regulation of MMP-9 production by human cornea epithelial cells. Exp. Eye Res. 73, 449-459 (2001).

138. Sobrin, L. et al. Regulation of MMP-9 activity in human tear fluid and corneal epithelial culture supernatant. Invest. Ophthalmol. Vis. Sci. 41, 1703-1709 (2000).

139. Asatsuma, M. et al. Increase in the ratio of matrix metalloproteinase- 9 to tissue inhibitor of metalloproteinase-1 in saliva from patients with primary Sjogren's syndrome. Clin. Chim. Acta 345, 99-104 (2004).

140. Branton, M.H. \& Kopp, J.B. TGF-beta and fibrosis. Microbes. Infect. 1, 1349-1365 (1999).

141. Bernauer, W., Wright, P., Dart, J.K., Leonard, J.N. \& Lightman, S. Cytokines in the conjunctiva of acute and chronic mucous membrane pemphigoid: an immunohistochemical analysis. Graefes Arch. Clin. Exp. Ophthalmol. 231, 563-570 (1993).

142. Hamrah, P., Liu, Y., Zhang, Q. \& Dana, M.R. The corneal stroma is endowed with a significant number of resident dendritic cells. Invest. Ophthalmol. Vis. Sci. 44, 581-589 (2003).
143. Rashid, S. et al. Topical omega- 3 and omega- 6 fatty acids for treatment of dry eye. Arch. Ophthalmol. 126, 219-225 (2008).

144. Yan, J. \& Mamula, M.J. B and T cell tolerance and autoimmunity in autoantibody transgenic mice. Int. Immunol. 14, 963-971 (2002).

145. Chan, O.T., Hannum, L.G., Haberman, A.M., Madaio, M.P. \& Shlomchik, M.J. A novel mouse with $B$ cells but lacking serum antibody reveals an antibody-independent role for B cells in murine lupus. J. Exp. Med. 189, 1639-1648 (1999).

146. Serreze, D.V. et al. B lymphocytes are critical antigen-presenting cells for the initiation of T cell-mediated autoimmune diabetes in nonobese diabetic mice. J. Immunol. 161, 3912-3918 (1998).

147. O'Neill, S.K. et al. Antigen-specific B cells are required as APCs and autoantibody-producing cells for induction of severe autoimmune arthritis. J. Immunol. 174, 3781-3788 (2005).

148. Rodriguez-Pinto, D. B cells as antigen presenting cells. Cell Immunol. 238, 67-75 (2005).

149. Rodriguez-Pinto, D. \& Moreno, J. B cells can prime naive CD4+ T cells in vivo in the absence of other professional antigen-presenting cells in a CD154-CD40-dependent manner. Eur. J. Immunol. 35, 1097-1105 (2005).

150. Batista, F.D. \& Neuberger, M.S. Affinity dependence of the B cell response to antigen: a threshold, a ceiling, and the importance of off-rate. Immunity 8, 751-759 (1998).

151. Knop, E. \& Knop, N. Influence of the eye-associated lymphoid tissue (EALT) on inflammatory ocular surface disease. Ocul. Surf. 3, S180-S186 (2005).

152. Routsias, J. \& Tzioufas, A. Sjogren's syndrome--study of autoantigens and autoantibodies. Clin. Rev. Allergy Immunol. 32, 238-251 (2007).

153. Bacman, S., Berra, A., Sterin-Borda, L. \& Borda, E. Muscarinic acetylcholine receptor antibodies as a new marker of dry eye Sjogren syndrome. Invest. Ophthalmol. Vis. Sci. 42, 321-327 (2001).

154. Ohlsson, M., Jonsson, R. \& Brokstad, K.A. Subcellular redistribution and surface exposure of the Ro52, Ro60 and La48 autoantigens during apoptosis in human ductal epithelial cells: a possible mechanism in the pathogenesis of Sjogren's syndrome. Scand. J. Immunol. 56, 456-469 (2002).

155. Baboonian, C. et al. Virus infection induces redistribution and membrane localization of the nuclear antigen La (SS-B): a possible mechanism for autoimmunity. Clin. Exp. Immunol. 78, 454-459 (1989).

156. Rose, C.M. et al. Accumulation of catalytically active proteases in lacrimal gland acinar cell endosomes during chronic ex vivo muscarinic receptor stimulation. Scand. J. Immunol. 61, 36-50 (2005).

157. Takada, K., Takiguchi, M., Konno, A. \& Inaba, M. Autoimmunity against a tissue kallikrein in IQI/Jic Mice: a model for Sjogren's syndrome. J. Biol. Chem. 280, 3982-3988 (2005).

158. Jiang, G. et al. A new model of experimental autoimmune keratoconjunctivitis sicca (KCS) induced in Lewis rat by the autoantigen Klk1b22. Invest. Ophthalmol. Vis. Sci. 50, 2245-2254 (2009).

159. Siemasko, K. et al. Klk13 is a putative autoantigen during the immunopathogenesis of experimental autoimmune lacrimal keratoconjunctivitis. ARVO (2010)Ref Type: Abstract.

160. Cua, D.J. et al. Interleukin-23 rather than interleukin-12 is the critical cytokine for autoimmune inflammation of the brain. Nature 421, 744-748 (2003).

161. Langrish, C.L. et al. IL-23 drives a pathogenic T cell population that induces autoimmune inflammation. J. Exp. Med. 201, 233-240 (2005).

162. Jones, D.T., Monroy, D., Ji, Z. \& Pflugfelder, S.C. Alterations of ocular surface gene expression in Sjogren's syndrome. Adv. Exp. Med. Biol. 438, 533-536 (1998).

163. Chauhan, S.K. et al. Autoimmunity in dry eye is due to resistance of Th17 to Treg suppression. J. Immunol. 182, 1247-1252 (2009).

164. El, A.J. et al. Characterization of effector T cells in dry eye disease. Invest Ophthalmol. Vis. Sci. 50, 3802-3807 (2009).

165. Enriquez-de-Salamanca, A. et al. Cytokine responses by conjunctival epithelial cells: an in vitro model of ocular inflammation. Cytokine 44, 160-167 (2008)

166. Ecoiffier, T., El, A.J., Rashid, S., Schaumberg, D. \& Dana, R. Modulation of integrin alpha4beta1 (VLA-4) in dry eye disease. Arch. Ophthalmol. 126, 1695-1699 (2008).

167. Goyal, S., Chauhan, S.K., Zhang, Q. \& Dana, R. Amelioration of murine dry eye disease by topical antagonist to chemokine receptor 2. Arch. Ophthalmol. 127, 882-887 (2009).

168. Tornwall, J., Lane, T.E., Fox, R.I. \& Fox, H.S. T cell attractant chemokine expression initiates lacrimal gland destruction in nonobese diabetic mice. Lab Invest 79, 1719-1726 (1999). 
169. Massingale, M.L. et al. Analysis of inflammatory cytokines in the tears of dry eye patients. Cornea 28, 1023-1027 (2009).

170. Pflugfelder, S.C. et al. Matrix metalloproteinase- 9 knockout confers resistance to corneal epithelial barrier disruption in experimental dry eye. Am. J. Pathol. 166, 61-71 (2005).

171. Yeh, S. et al. Apoptosis of ocular surface cells in experimentally induced dry eye. Invest Ophthalmol. Vis. Sci. 44, 124-129 (2003).

172. Albertsmeyer, A.C., Kakkassery, V., Spurr-Michaud, S., Beeks, O. \& Gipson, I.K. Effect of pro-inflammatory mediators on membraneassociated mucins expressed by human ocular surface epithelial cells. Exp. Eye Res. 90, 444-451 (2009).

173. Corrales, R.M. et al. Strain related cytokine profiles on the murine ocular surface in response to desiccating stress. Cornea 26, 578-584 (2007).

174. O'Brien, R. et al. Characteristics of IL-17-producing gammadelta T cells. Immunity 32, 1-4 (2010).

175. Cui, Y. et al. Major role of gamma delta T cells in the generation of IL-17+ uveitogenic T cells. J. Immunol. 183, 560-567 (2009).

176. Leadbetter, E.A., Rifkin, I.R. \& Marshak-Rothstein, A. Toll-like receptors and activation of autoreactive B cells. Curr. Dir. Autoimmun. 6, 105-122 (2003).

177. Shlomchik, M.J. Activating systemic autoimmunity: B's, T's, and tolls. Curr. Opin. Immunol. 21, 626-633 (2009).

178. Groom, J. \& Mackay, F. B cells flying solo. Immunol. Cell Biol. 86, 40-46 (2008).

179. Lund, F.E. Cytokine-producing B lymphocytes-key regulators of immunity. Curr. Opin. Immunol. 20, 332-338 (2008).

180. Leadbetter, E.A. et al. Chromatin-lgG complexes activate B cells by dual engagement of IgM and Toll-like receptors. Nature 416, 603-607 (2002).

181. Lau, C.M. et al. RNA-associated autoantigens activate $B$ cells by combined B cell antigen receptor/Toll-like receptor 7 engagement. J. Exp. Med. 202, 1171-1177 (2005).

182. Viglianti, G.A. et al. Activation of autoreactive B cells by $\mathrm{CpG}$ dsDNA. Immunity 19, 837-847 (2003).

183. Christensen, S.R. et al. Toll-like receptor 7 and TLR9 dictate autoantibody specificity and have opposing inflammatory and regulatory roles in a murine model of lupus. Immunity 25, 417-428 (2006).

184. Christensen, S.R. et al. Toll-like receptor 9 controls anti-DNA autoantibody production in murine lupus. J. Exp. Med. 202, 321-331 (2005).

185. Herlands, R.A., Christensen, S.R., Sweet, R.A., Hershberg, U. \& Shlomchik, M.J. T cell-independent and toll-like receptor-dependent antigen-driven activation of autoreactive B cells. Immunity 29, 249-260 (2008).

186. Mackay, F., Groom, J.R. \& Tangye, S.G. An important role for B-cell activation factor and B cells in the pathogenesis of Sjogren's syndrome. Curr. Opin. Rheumatol. 19, 406-413 (2007).
187. Schiemann, B. et al. An essential role for BAFF in the normal development of B cells through a BCMA-independent pathway. Science 293, 2111-2114 (2001).

188. Mackay, F. et al. Mice transgenic for BAFF develop lymphocytic disorders along with autoimmune manifestations. J. Exp. Med. 190, 1697-1710 (1999).

189. Groom, J. et al. Association of BAFF/BLyS overexpression and altered B cell differentiation with Sjogren's syndrome. J. Clin. Invest 109, 59-68 (2002).

190. Thien, M. et al. Excess BAFF rescues self-reactive B cells from peripheral deletion and allows them to enter forbidden follicular and marginal zone niches. Immunity 20, 785-798 (2004).

191. Fletcher, C.A. et al. Development of nephritis but not sialadenitis in autoimmune-prone BAFF transgenic mice lacking marginal zone B cells. Eur. J. Immunol. 36, 2504-2514 (2006).

192. Oliver, A.M., Martin, F., Gartland, G.L., Carter, R.H. \& Kearney, J.F. Marginal zone $B$ cells exhibit unique activation, proliferative and immunoglobulin secretory responses. Eur. J. Immunol. 27, 2366-2374 (1997).

193. Attanavanich, K. \& Kearney, J.F. Marginal zone, but not follicular B cells, are potent activators of naive CD4T cells. J. Immunol. 172, 803-811 (2004).

194. Mariette, X. et al. The level of BLyS (BAFF) correlates with the titre of autoantibodies in human Sjogren's syndrome. Ann. Rheum. Dis. 62, 168-171 (2003).

195. Lavie, F. et al. B-cell activating factor of the tumour necrosis factor family expression in blood monocytes and T cells from patients with primary Sjogren's syndrome. Scand. J. Immunol. 67, 185-192 (2008).

196. Daridon, C. et al. Aberrant expression of BAFF by B lymphocytes infiltrating the salivary glands of patients with primary Sjogren's syndrome. Arthritis Rheum. 56, 1134-1144 (2007).

197. Szodoray, P. et al. Distinct profiles of Sjogren's syndrome patients with ectopic salivary gland germinal centers revealed by serum cytokines and BAFF. Clin. Immunol. 117, 168-176 (2005).

198. Ittah, M. et al. B cell-activating factor of the tumor necrosis factor family (BAFF) is expressed under stimulation by interferon in salivary gland epithelial cells in primary Sjogren's syndrome. Arthritis Res. Ther. 8, R51 (2006).

199. Ittah, M. et al. Viruses induce high expression of BAFF by salivary gland epithelial cells through TLR- and type-I IFN-dependent and -independent pathways. Eur. J. Immunol. 38, 1058-1064 (2008).

200. Robinson, C.P. et al. Transfer of human serum IgG to nonobese diabetic Igmu null mice reveals a role for autoantibodies in the loss of secretory function of exocrine tissues in Sjogren's syndrome. Proc. Natl. Acad. Sci. USA 95, 7538-7543 (1998). 